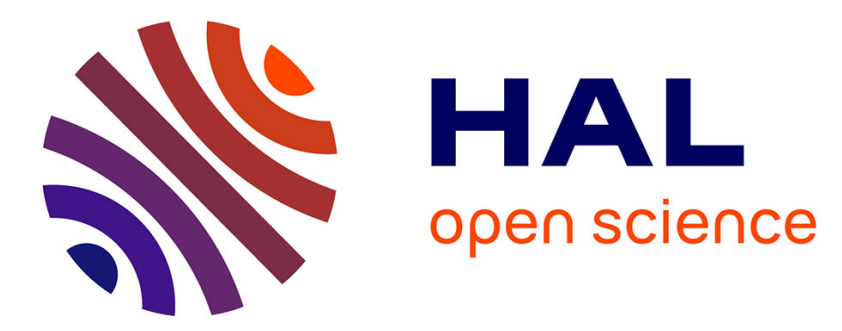

\title{
Conducting polymers synthesized by $\gamma$-radiolysis in very acidic aqueous medium
}

Fabrice Goubard, Zhenpeng Cui, Teseer Bahry, Alexandre Dazzi, Thanh-Tuân Bui, Samy Remita

\section{- To cite this version:}

Fabrice Goubard, Zhenpeng Cui, Teseer Bahry, Alexandre Dazzi, Thanh-Tuân Bui, et al.. Conducting polymers synthesized by $\gamma$-radiolysis in very acidic aqueous medium. Radiation Physics and Chemistry, 2019, 159, pp.47-56. 10.1016/j.radphyschem.2019.02.026 . hal-03469539

\section{HAL Id: hal-03469539 \\ https://hal.science/hal-03469539}

Submitted on 20 Dec 2021

HAL is a multi-disciplinary open access archive for the deposit and dissemination of scientific research documents, whether they are published or not. The documents may come from teaching and research institutions in France or abroad, or from public or private research centers.
L'archive ouverte pluridisciplinaire HAL, est destinée au dépôt et à la diffusion de documents scientifiques de niveau recherche, publiés ou non, émanant des établissements d'enseignement et de recherche français ou étrangers, des laboratoires publics ou privés.

\section{다(1) $\$$}

Distributed under a Creative Commons Attribution - NonCommerciall 4.0 International 


\title{
Conducting polymers synthesized by $\gamma$-radiolysis in very acidic aqueous medium
}

\section{Zhenpeng Cui a, Teseer Bahry a , Alexandre Dazzi a, Thanh-Tuân Bui ${ }^{\text {b, }}$ Fabrice Goubard ${ }^{b}$ and Samy Remita ${ }^{\text {a,c * }}$}

\begin{abstract}
a Laboratoire de Chimie Physique, LCP, UMR 8000, CNRS, Université Paris-Sud, Campus d'Orsay, 15 avenue Jean Perrin, 91405 Orsay Cedex, France.

${ }^{b}$ Laboratoire de Physicochimie des Polymères et Interfaces, LPPI, EA 2528, Université de CergyPontoise, 5 mail Gay Lussac, Neuville sur Oise, 95031 Cergy-Pontoise Cedex, France.

${ }^{\mathrm{c}}$ Department of Health, Life and Chemical Sciences, EPN 7, Conservatoire National des Arts et Métiers, CNAM, 292 rue Saint-Martin, 75141 Paris Cedex 03, France.
\end{abstract}

*Corresponding author. E-mail: samy.remita@u-psud.fr. Tel.: +33 (0)1 69154441

Keywords: Radiolysis, conducting polymers, PEDOT, dichloride radical anion

\begin{abstract}
In this work, conducting polymers were synthesized for the first time in acidic aqueous solutions by means of $\gamma$-irradiation. Poly(3,4-ethylenedioxythiophene) (PEDOT) polymers were prepared under $\mathrm{N}_{2} \mathrm{O}$ atmosphere in the presence of highly concentrated hydrochloric acid $(\mathrm{HCl})$ at $\mathrm{pH} \sim 0$, thanks to the oxidation of 3,4ethylenedioxythiophene (EDOT) monomers by $\mathrm{Cl}_{2}{ }^{-\bullet}$ oxidizing radicals produced in the medium by water radiolysis. UV-Vis absorption spectroscopy was used to estimate the radiolytic yield of EDOT oxidation as well as the required dose for quantitative PEDOT preparation. After a 72-kGy irradiation, PEDOT polymers, which form dark blue suspensions, were characterized by a large absorption band at around $700 \mathrm{~nm}$. Size exclusion chromatography demonstrated that these radiosynthesized PEDOT polymers contain up to 20 EDOT units. After deposition, ATR-FTIR spectroscopy and Energy-Dispersive X-ray (EDX) analysis highlighted the doping of PEDOT polymers prepared in the presence of $\mathrm{HCl}$. The morphology of radiosynthesized PEDOT polymers was characterized by SEM microscopy and by high-resolution AFM-IR microscopy coupled with infrared nanospectroscopy. Aggregated spheroidal PEDOT particles with diameters comprised between 200 and
\end{abstract}


$500 \mathrm{~nm}$ were detected. In addition, cyclic voltammetry (CV) and four-point probe measurements demonstrated that PEDOT polymers radiosynthesized in very acidic medium are characterized by prominent electronic properties (small band gap and considerable electrical conductivity). Promisingly, the present radiolytic study should offer a new synthetic approach for the preparation in acidic aqueous media of conducting polymers with enhanced properties.

\section{Introduction}

Conducting polymers (CPs) possess intrinsic electrical conductivity due to the unique $\pi$-conjugated systems along the polymer chains (Li et al., 2009; Shirakawa, 2001). As the fourth generation of polymeric materials (Heeger, 2001a, b), CPs are also called "synthetic metals" and have attracted great research interest for their potential applications (MacDiarmid, 2001), such as organic conductors (Cho et al., 2014), biomaterials (Balint et al., 2014), electrochromic windows (Heuer et al., 2002) and solar cells ( $\mathrm{Na}$ et al., 2008). To date, various electrical conducting polymers have been developed (Heeger, 2001b), among which poly(3,4-ethylenedioxythiophene) (PEDOT, Scheme 1) has been widely investigated for its easy synthesis, good stability and high conductivity (Roncali et al., 2005; Groenendaal et al., 2000).

In general, polymerization of 3,4-ethylenedioxythiophene (EDOT, Scheme 1) monomers can be achieved by both traditional chemical (Zhang et al., 2005; Bashir et al., 2014) and electrochemical methods (Xiao et al., 2007; Akoudad and Roncali, 1998). In addition to the traditional synthetic routes, alternative approaches such as microwave-assisted (Dong et al., 2013) and enzyme-catalyzed polymerizations have also been reported (Rumbau et al., 2007). In our previous work, gamma-irradiation induced polymerization of EDOT monomers was successfully carried out enabling the development of an easy and clean alternative methodology for the preparation of PEDOT polymers (Lattach et al., 2013; Cui et al., 2017).

With radiolytic method, nanostructured PEDOT materials were obtained by EDOT oxidation using either hydroxyl radical (HO') (Lattach et al., 2013; Lattach et al., 2014) or azide radical $\left(\mathrm{N}_{3}{ }^{\circ}\right)$ (Lattach et al., 2014) and even by EDOT reduction thanks to the use of hydrated electron $\left(\mathrm{e}_{\mathrm{aq}}{ }^{-}\right)$generated by water radiolysis (Cui et al., 2016). Interestingly, morphology of PEDOT polymers was found dependent on the 
nature of the initiating radiolytic species: while $\mathrm{HO}^{-}$and $\mathrm{e}_{\mathrm{aq}}^{-}$lead to spherical nanoparticles, $\mathrm{N}_{3}{ }^{\bullet}$ leads to fibrillar structures (Lattach et al., 2014).

It is worth noting that all the above works were conducted by our team in neutral aqueous solutions and never in acidic aqueous media even though low pHs were shown in literature to prevent conducting polymers overoxidation (Tehrani et al., 2007) and to improve their electrical conductivity by doping effect (Ouyang, 2013) and structural optimization (Yun et al., 2016). We therefore wanted to use $\gamma$ irradiation in order to radiolytically prepare for the first time conducting organic materials in acidic aqueous media and then to study their properties.

In this work, we extend our methodology based on radiation chemistry in order to polymerize, under $\mathrm{N}_{2} \mathrm{O}$, EDOT monomers in very acidic aqueous solutions (in presence of $\mathrm{HClO}_{4}$ or $\mathrm{HCl}$ at $\mathrm{pH} \sim 0$ ), by exploiting the oxidizing species produced by $\gamma$-radiolysis $\left(\mathrm{HO}^{*}\right.$ or $\left.\mathrm{Cl}_{2}{ }^{-}\right)$. The as-prepared PEDOT polymers are then characterized in solution and after deposition by complementary techniques and are compared with those usually synthesized in neutral aqueous media under the same atmosphere $\left(\mathrm{N}_{2} \mathrm{O}\right)$. The specific influence of the acidity of the medium on morphological, optical and electrical properties of radiosynthesized PEDOT polymers is then discussed.

\section{Materials and methods}

\subsection{Chemical products}

3,4-ethylenedioxythiophene (EDOT) $(\geq 98 \%$, Sigma-Aldrich) was used as the monomer at a final concentration of 1 or $10 \mathrm{mM}$ while ultra-pure water (Millipore system, 18.2 $\mathrm{M} \Omega \mathrm{cm})$ was used as the solvent. Hydrochloric acid $(\mathrm{HCl})(37 \%$, ACS reagent) or perchloric acid $\left(\mathrm{HClO}_{4}\right)$ were used at a concentration of $1 \mathrm{M}$ in order to get a $\mathrm{pH}$ value of the aqueous solution close to 0 . Nitrous oxide gas $\left(\mathrm{N}_{2} \mathrm{O}\right)$ (Air Liquid Co.) was used for degassing. Nitrosyl tetrafluoroborate $\left(\mathrm{NOBF}_{4}\right)(\geq 95 \%$, SigmaAldrich) was dissolved in acetonitrile ( $\geq 99.9 \%$, Sigma-Aldrich) and used as dopant for $p$-doping of PEDOT polymers during four-point probe measurements. All experiments were conducted at ambient temperature. 


\subsection{Radiolysis of acidic aqueous solutions under $\mathrm{N}_{2} \mathrm{O}$}

It is well known that water radiolysis at neutral $\mathrm{pH}$ under nitrogen $\left(\mathrm{N}_{2}\right)$ atmosphere produces various species (Spinks and Woods, 1990; Ferradini and JayGerin, 1999; Ferradini and Jay-Gerin, 2000) according to:

$$
\mathrm{H}_{2} \mathrm{O} \sim \sim \sim \mathrm{e}_{\mathrm{aq}}{ }^{-}, \mathrm{HO}^{\bullet}, \mathrm{H}^{\bullet}, \mathrm{H}_{3} \mathrm{O}^{+}, \mathrm{H}_{2} \mathrm{O}_{2}, \mathrm{H}_{2}
$$

In these deaerated conditions and at a neutral $\mathrm{pH}$, the radiolytic yields, $\mathrm{G}$ values, of the most reactive radical species $\left(\mathrm{e}_{\mathrm{aq}}{ }^{-}, \mathrm{HO}^{\circ}\right.$ and $\left.\mathrm{H}^{\circ}\right)$ are:

$$
\begin{aligned}
& \mathrm{G}_{\mathrm{e}_{\mathrm{aq}}{ }^{-}}=2.8 \times 10^{-7} \mathrm{~mol} \mathrm{~J}^{-1} \\
& \mathrm{G}_{\mathrm{HO}}=2.8 \times 10^{-7} \mathrm{~mol} \mathrm{~J}^{-1} \\
& \mathrm{G}_{\mathrm{H}^{\bullet}}=0.6 \times 10^{-7} \mathrm{~mol} \mathrm{~J}^{-1}
\end{aligned}
$$

Among these radicals, solvated electron $\left(\mathrm{e}_{\mathrm{aq}}{ }^{-}\right)$and hydroxyl radical $\left(\mathrm{HO}^{\circ}\right)$ are the most abundant and reactive species (Ferradini and Jay-Gerin, 2000). Indeed, $\mathrm{e}_{\mathrm{aq}}{ }^{-}$is a very reducing species with a redox potential of $-2.8 \mathrm{~V}_{\mathrm{SHE}}$ (Spinks and Woods, 1990; Schwarz, 1981) while $\mathrm{HO}^{\circ}$ is a strong oxidizing species with an apparent standard redox potential which amounts to $\mathrm{E}^{\circ}\left(\mathrm{HO}^{\circ} / \mathrm{H}_{2} \mathrm{O}\right)=2.2 \mathrm{~V}_{\text {SHE }}$ at $\mathrm{pH}=7$ (Buxton et al., 1988).

When, at neutral $\mathrm{pH}$, irradiated aqueous solutions are saturated with nitrous oxide, $\mathrm{e}_{\mathrm{aq}}^{-}$is quantitatively converted into $\mathrm{HO}^{\bullet}$ radical according to the following reaction (Hart, 1969):

$$
\mathrm{e}_{\mathrm{aq}}{ }^{-}+\mathrm{N}_{2} \mathrm{O}+\mathrm{H}_{2} \mathrm{O} \rightarrow \mathrm{HO}^{\bullet}+\mathrm{HO}^{-}+\mathrm{N}_{2}
$$

As a consequence, radiolytic yields of production of both $\mathrm{e}_{\mathrm{aq}}{ }^{-}$and $\mathrm{HO}^{\bullet}$ species are modified in presence of $\mathrm{N}_{2} \mathrm{O}$.

The $\mathrm{G}$ values of radiolytic species depend not only on the atmosphere $\left(\mathrm{N}_{2} \mathrm{O}\right.$ or $\mathrm{N}_{2}$ ), but also on the $\mathrm{pH}$ value of the aqueous solution. Indeed, when water radiolysis happens in acidic medium, $\mathrm{e}_{\mathrm{aq}}{ }^{-}$is quickly transformed into its acidic form, namely hydrogen atom $\left(\mathrm{H}^{*}\right)$, by reacting with hydrogen ion $\left(\mathrm{H}^{+}\right)$(Spinks and Woods, 1990): 


$$
\mathrm{e}_{\mathrm{aq}}{ }^{-}+\mathrm{H}^{+} \rightarrow \mathrm{H}^{\cdot}
$$

Now, if we consider radiolysis of water under $\mathrm{N}_{2} \mathrm{O}$ atmosphere and at very low $\mathrm{pH}\left(\mathrm{pH} \sim 0\right.$, in presence of $1 \mathrm{M}$ in perchloric acid, $\mathrm{HClO}_{4}$, for instance), which corresponds to the experimental conditions used in the present paper, hydrated electrons are quickly scavenged according to the two competitive reactions (5) and (6). Let us then consider these two competitive reactions of $\mathrm{e}_{\mathrm{aq}}{ }^{-}$onto $\mathrm{N}_{2} \mathrm{O}$ (leading to additional $\mathrm{HO}^{\bullet}$ radicals) and onto $\mathrm{H}^{+}$(leading to additional $\mathrm{H}^{\bullet}$ atoms) which induce the total consumption of hydrated electrons. The branching ratio $(\mathrm{R})$ between these two competitive reactions, which corresponds to the ratio between the additional amount of $\mathrm{HO}^{\circ}$ and that of $\mathrm{H}^{\bullet}$ produced by reactions (5) and (6) respectively, can be expressed as:

$$
\mathrm{R}=\frac{\mathrm{G}_{\mathrm{HO}}^{\prime}}{\mathrm{G}_{\mathrm{H}^{\cdot}}^{\prime}}=\frac{\mathrm{k}_{\mathrm{N}_{2} \mathrm{O}}\left[\mathrm{N}_{2} \mathrm{O}\right]}{\mathrm{k}_{\mathrm{H}^{+}}\left[\mathrm{H}^{+}\right]}
$$

where $\left[\mathrm{N}_{2} \mathrm{O}\right]$ and $\left[\mathrm{H}^{+}\right]$are the concentrations in $\mathrm{N}_{2} \mathrm{O}$ and $\mathrm{H}^{+}$, where $\mathrm{k}_{\mathrm{N}_{2} \mathrm{O}}$ and $\mathrm{kH}^{+}$are the rate constants of reactions (5) and (6) respectively and where $\mathrm{G}_{\mathrm{HO}}^{\prime} \cdot$ and $\mathrm{G}_{\mathrm{H}}^{\prime}$. are the radiolytic yields of production of the additional amounts in $\mathrm{HO}^{\bullet}$ and $\mathrm{H}^{\bullet}$ according to reactions (5) and (6). Note that:

$$
\mathrm{G}^{\prime} \mathrm{HO}^{\bullet}+\mathrm{G}_{\mathrm{H}^{\prime}}=\mathrm{G}_{\mathrm{e}_{\mathrm{aq}}{ }^{-}}=2.8 \times 10^{-7} \mathrm{~mol} \mathrm{~J}^{-1}
$$

Taking into consideration the effective values of the concentrations $\left(\left[\mathrm{N}_{2} \mathrm{O}\right]=\right.$ $0.0265 \mathrm{~mol} \mathrm{~L}^{-1}$ and $\left.\left[\mathrm{H}^{+}\right]=10^{-\mathrm{pH}}=1 \mathrm{~mol} \mathrm{~L}^{-1}\right)$ as well as the rate constants values $\left(\mathrm{k}_{\mathrm{N}_{2} \mathrm{O}}\right.$ $=9 \times 10^{9} \mathrm{~L} \mathrm{~mol}^{-1} \mathrm{~s}^{-1}$ and $\mathrm{kH}^{+}=2.3 \times 10^{10} \mathrm{~L} \mathrm{~mol}^{-1} \mathrm{~s}^{-1}$ ) (Buxton et al., 1988; Hart, 1969), one can calculate the branching ratio, $\mathrm{R}$, at $\mathrm{pH} \sim 0: \mathrm{R}=0.01$. This calculation indicates without any ambiguity that only one hundred percent of hydrated electrons are converted, under $\mathrm{N}_{2} \mathrm{O}$ at $\mathrm{pH} \sim 0$, into $\mathrm{HO}^{\bullet}\left(\mathrm{G}^{\prime} \mathrm{HO}^{\bullet} \sim 0\right)$. In fact, nearly all $\mathrm{e}_{\mathrm{aq}}{ }^{-}$are converted into $\mathrm{H}^{\bullet}$ atoms $\left(\mathrm{G}^{\prime} \mathrm{H}^{\cdot} \sim \mathrm{G}_{\mathrm{e}_{\mathrm{aq}}{ }^{-}}=2.8 \times 10^{-7} \mathrm{~mol} \mathrm{~J}{ }^{-1}\right)$. It is then possible to evaluate, under $\mathrm{N}_{2} \mathrm{O}$ at $\mathrm{pH} \sim 0$, the total radiolytic yields of production of $\mathrm{HO}^{*}$ radicals and of $\mathrm{H}^{\bullet}$ atoms according to: 


$$
\begin{aligned}
& \mathrm{G}\left(\mathrm{HO}^{\bullet}\right)=\mathrm{G}_{\mathrm{HO}}{ }^{\bullet}+\mathrm{G}^{\prime} \mathrm{HO}^{\bullet}=2.8 \times 10^{-7} \mathrm{~mol} \mathrm{~J}^{-1} \\
& \mathrm{G}\left(\mathrm{H}^{\bullet}\right)=\mathrm{GH}^{\bullet}+\mathrm{G}^{\prime}{ }^{\bullet}=0.6 \times 10^{-7}+2.8 \times 10^{-7}=3.4 \times 10^{-7} \mathrm{~mol} \mathrm{~J}^{-1}
\end{aligned}
$$

In very acidic medium and under $\mathrm{N}_{2} \mathrm{O}$, two reactive species should then be considered: $\mathrm{HO}^{\circ}$ and $\mathrm{H}^{*}$. This is the case when perchloric acid $\left(\mathrm{HClO}_{4}\right)$ is used to adjust the $\mathrm{pH}$ of the aqueous solution. Indeed, perchlorate ions $\left(\mathrm{ClO}_{4}{ }^{-}\right)$remain unreactive upon radiolysis. While $\mathrm{HO}^{\bullet}$ is known as a very oxidizing species which enables in particular oxidation-induced polymerization of EDOT monomers in neutral aqueous solutions, $\mathrm{H}^{\bullet}$ is less reactive and its reactions are often neglected in neutral media due to its low $\mathrm{G}$ value at $\mathrm{pH}=7$ (Coletta et al., 2015). Nevertheless, as highlighted thanks to equations (9) and (10), $\mathrm{H}^{\bullet}$ becomes predominant at $\mathrm{pH} \sim 0$ and thus its reactivity onto EDOT monomers cannot be omitted as demonstrated in some cases in literature (Saunders, 1978).

Interestingly, when hydrochloride acid $(\mathrm{HCl})$ is used (instead of $\mathrm{HClO}_{4}$ ) in order to adjust the $\mathrm{pH}, \mathrm{HO}^{\bullet}$ radicals are quantitatively transformed into dichloride radical anions, $\mathrm{Cl}_{2}{ }^{--}$, according to the following reactions (Jayson et al., 1973):

$$
\begin{aligned}
& \mathrm{HO}^{\bullet}+\mathrm{Cl}^{-} \rightarrow \mathrm{ClOH}^{-} \\
& \mathrm{ClOH}^{\bullet-}+\mathrm{H}^{+} \rightarrow \mathrm{Cl}^{\bullet}+\mathrm{H}_{2} \mathrm{O} \\
& \mathrm{Cl}^{\bullet}+\mathrm{Cl}^{-} \rightarrow \mathrm{Cl}_{2}^{\cdot-}
\end{aligned}
$$

Therefore, the main species produced by $\gamma$-radiolysis of very acidic aqueous solutions containing $\mathrm{HCl}$ under $\mathrm{N}_{2} \mathrm{O}$ are $\mathrm{Cl}_{2}{ }^{-}$(instead of $\mathrm{HO}^{\circ}$ ) and $\mathrm{H}^{\bullet}$ (Elliot et al., 1988). Under $\mathrm{N}_{2} \mathrm{O}$ and at $\mathrm{pH} \sim 0$, while the total radiolytic yield of production of $\mathrm{H}^{\bullet}$ atoms remains the same as that found in the case of $\mathrm{HClO}_{4}$ (equation (10)), that of $\mathrm{Cl}_{2}{ }^{-}$can be easily deduced from equation (9):

$$
\mathrm{G}\left(\mathrm{Cl}_{2}{ }^{\bullet-}\right)=2.8 \times 10^{-7} \mathrm{~mol} \mathrm{~J}^{-1}
$$

Such as $\mathrm{HO}^{\circ}, \mathrm{Cl}_{2}{ }^{-}$is a strong oxidizing species with a very high standard redox potential: $\mathrm{E}^{\circ}\left(\mathrm{Cl}_{2}{ }^{-} / \mathrm{Cl}^{-}\right)=2.1 \mathrm{~V}_{\mathrm{SHE}}$ (Schwarz and Dodson, 1984). This should enable, as in the case of hydroxyl radicals, the oxidation of EDOT monomers by $\mathrm{Cl}_{2}{ }^{--}$and their polymerization into PEDOT. 


\subsection{Radiation induced synthesis of PEDOT polymers in acidic aqueous medium}

As demonstrated in our previous study (Coletta et al., 2015), conducting polymers growth proceeds through a step-by-step mechanism. In this context, radiation induced polymerization of EDOT implies recurrent oxidation reactions induced by oxidizing radicals: oxidation of monomers followed by that of dimers, tetramers, oligomers... According to this growth mechanism, the amount of oxidative radicals which is needed for quantitative formation of PEDOT polymers is twice that of EDOT monomers. As a consequence, the absorbed dose, D (expressed in Grays, 1 Gy corresponding to $1 \mathrm{~J} \mathrm{~kg}^{-1}$ ) (Mlekodaj, 1995), which should lead to the quantitative production of PEDOT polymers is the double of the one required for the total oxidation of EDOT monomers (Coletta et al., 2015):

$$
\mathrm{D}(\mathrm{Gy})=\frac{2\left[\mathrm{EDOT}_{0}\left(\mathrm{~mol} \mathrm{~L}^{-1}\right)\right.}{\mathrm{G}_{\mathrm{Ox}}\left(\mathrm{mol} \mathrm{J}^{-1}\right) \mathrm{d}\left(\mathrm{kg} \mathrm{L}^{-1}\right)}
$$

where $[E D O T]_{0}$ is the initial concentration of EDOT, where $G_{o x}$ is the effective yield of EDOT oxidation and where $\mathrm{d}$ is the density $\left(\mathrm{d}=1 \mathrm{~kg} \mathrm{~L}^{-1}\right.$ in case of water).

If we suppose that, under $\mathrm{N}_{2} \mathrm{O}$ at $\mathrm{pH} \sim 0$, in presence of $\mathrm{HClO}_{4}$ or $\mathrm{HCl}, \mathrm{HO}{ }^{\bullet}$ or $\mathrm{Cl}_{2}{ }^{\circ-}$ quantitatively oxidize EDOT and if we assume that $\mathrm{H}^{*}$ remains unreactive, then the effective yield of EDOT oxidation, $\mathrm{G}_{\mathrm{ox}}$, corresponds to the total radiolytic yield of production of $\mathrm{HO}^{\circ}, \mathrm{G}\left(\mathrm{HO}^{*}\right)$, or to that of $\mathrm{Cl}_{2}{ }^{-}, \mathrm{G}\left(\mathrm{Cl}_{2}{ }^{-}\right)$(see equations (9) and (14)):

$$
\mathrm{G}_{\mathrm{ox}}=2.8 \times 10^{-7} \mathrm{~mol} \mathrm{~J}^{-1}
$$

This will be confirmed later in the manuscript in results and discussion section. Then, if we consider the value of the oxidation yield given by equation (16), the dose required for quantitative polymerization of EDOT amounts to $72 \mathrm{kGy}$ in the case of a $\mathrm{N}_{2} \mathrm{O}$-saturated aqueous solution containing $10 \mathrm{mM}$ in EDOT at $\mathrm{pH} \sim 0$ (in presence of $\mathrm{HCl}$ or $\mathrm{HClO}_{4}$ ).

Aqueous solutions of different concentrations of EDOT ranging between 1 and $10 \mathrm{mM}$ were first prepared at room temperature in presence of $\mathrm{HClO}_{4}$ or $\mathrm{HCl}$ at a 
concentration of $1 \mathrm{M}$ in order to adjust the $\mathrm{pH}$ at 0 . The $\mathrm{pH}$ value of each solution was measured by using a pH-meter (CyberScan pH 500). The solutions were then degassed and saturated with $\mathrm{N}_{2} \mathrm{O}$ for $20 \mathrm{~min}$ and finally irradiated, using a ${ }^{60} \mathrm{Co}$ panoramic $\gamma$-ray source at LCP laboratory, with increasing doses up to $72 \mathrm{kGy}$ in order to quantitatively synthesize PEDOT polymers. In all experiments, the dose rate was $5 \mathrm{kGy} \mathrm{h}^{-1}$.

\subsection{Characterization of PEDOT polymers}

Ultraviolet-visible (UV-Vis) absorption spectrophotometry was used to study the optical properties of EDOT monomers and of PEDOT polymers prepared in acidic aqueous solutions (at $\mathrm{pH} \sim 0$ in presence of $\mathrm{HCl}$ or $\mathrm{HClO}_{4}$ ) as a function of the dose. Absorption spectra were recorded on a HP $8453 \mathrm{UV}-\mathrm{Vis}$ spectrophotometer using quartz cells with optical path lengths of $0.2 \mathrm{~cm}$. The reference was always pure water.

After irradiation, in order to extract PEDOT polymers, irradiated solutions were dried under reduced pressure. The obtained powders were washed with ethanol and water in order to eliminate residual EDOT monomers, then dried in the oven at $50{ }^{\circ} \mathrm{C}$ for $24 \mathrm{~h}$. The washed PEDOT powders were finally used for further characterizations.

Attenuated total reflectance Fourier transform infrared (ATR-FTIR) spectroscopy was used for chemical characterization of PEDOT powders obtained after a 72-kGy irradiation in presence of $\mathrm{HCl}$ at $\mathrm{pH} \sim 0$. The spectra were recorded on a Bruker Vertex 70 FTIR spectrometer with a diamond ATR attachment (PIKEMIRACLE crystal plate diamond/ZnSe) and MCT detector equipped with a liquid nitrogen cooling system. The washed solid samples were placed on the diamond substrate of the apparatus and scanned from 4000 to $600 \mathrm{~cm}^{-1}$ with a resolution of $4 \mathrm{~cm}^{-1}$ for 100 times.

Size exclusion chromatography (SEC) was used to estimate the average molecular weight of PEDOT polymers synthesized in acidic aqueous medium (in presence of $\mathrm{HCl}$ ) at $72 \mathrm{kGy}$. After solvent evaporation and washing, powder made of radiosynthesized PEDOT polymers was dissolved in tetrahydrofuran (THF) solvent by stirring for $24 \mathrm{~h}$ and then $100 \mu \mathrm{L}$ of the obtained solution was injected into SEC apparatus. SEC was performed at $40{ }^{\circ} \mathrm{C}$ on a Malvern Viscotek TDA device equipped with two columns, Malvern T3000 and T6000, with a Malvern refractive index 
detector at an elution rate of $1 \mathrm{~mL} \mathrm{m^{-1 }}$. Polystyrene polymers were used as standards and THF as eluent

Scanning electron microscopy (SEM) was used to check the morphology of PEDOT polymers synthesized in acidic aqueous solution (in presence of $\mathrm{HCl}$ ) after a 72-kGy irradiation. The dried polymers powders were first sprinkled onto carbon tape adhered to aluminum mounts and then coated with gold and finally imaged by an EVO MA 10 Zeiss microscope. The applied voltage was $15 \mathrm{kV}$ and the scale bar was $1 \mu \mathrm{m}$. During SEM observations, in situ energy dispersive X-Ray spectroscopy (EDX) was carried out (without gold coating) to check the chemical composition and to perform the elemental analysis of the solid powders within a selected area of the samples. The EDX spectra were recorded with a beam energy of $15 \mathrm{keV}$.

Atomic force microscopy coupled with infrared nanospectroscopy (AFM-IR) was performed to further study the morphology and composition of the radiosynthesized PEDOT polymers synthesized at $72 \mathrm{kGy}$ in acidic aqueous solution (in presence of $\mathrm{HCl}$ ). After irradiation and water evaporation, the blue dark powder made of PEDOT polymers was solubilized in ethanol and then few drops of the skyblue ethanolic solution were deposited onto the upper surface of ZnSe prism of AFMIR apparatus and dried at air. The system used in this work was a nanoIR (@Anasys Instruments) which combines an AFM microscope with an infrared pulse source. The microscope was used in contact mode while the pulsed infrared laser setup was covering the IR range from 3600 to $1000 \mathrm{~cm}^{-1}$. During all the measurements, the tip of the AFM microscope remained in contact with the surface of the sample. As described in our previous works, absorption by the sample of IR laser pulse causes AFM cantilever oscillation. The fact that the amplitude of cantilever oscillation is proportional to the intensity of the absorption originally enables the recording of the local infrared spectrum at a fixed position of the tip (by changing the wavenumber of the IR laser source) and the acquisition of a chemical map of the sample (by scanning the surface at a characteristic wavenumber).

Cyclic voltammetry (CV) was used in order to investigate the electrochemical properties and to determine the electrochemical band gap of PEDOT polymers radiosynthesized at $72 \mathrm{kGy}$ in acidic aqueous solution at $\mathrm{pH} \sim 0$ (in presence of $\mathrm{HCl}$ ). The electrochemical setup was a three-electrodes cell made of $\mathrm{Pt}$ disc as working electrode, an $\mathrm{Au}$ wire as counter-electrode and an $\mathrm{Ag} / \mathrm{AgCl}$ wire as pseudo-reference electrode. Calibration of pseudo-reference electrode was ensured by probing 
ferrocenium/ferrocene $\left(\mathrm{Fc}^{+} / \mathrm{Fc}\right)$ redox potential measured at the end of each experiment, as recommended by IUPAC. PEDOT powder $(1 \mathrm{mg})$ obtained after irradiation and after solvent evaporation was dissolved in $5 \mathrm{~mL}$ of acetonitrile solution containing $0.1 \mathrm{M}$ in tetrabutylammonium hexafluorophosphate, $\mathrm{TBAPF}_{6}$, used as electrolyte. The cyclic voltammograms were all recorded between $-2.5 \mathrm{~V}$ and $+2.5 \mathrm{~V}$ at a scan rate of $20 \mathrm{mV} \mathrm{s}^{-1}$.

Four-point probe technique was finally used in order to evaluate the electrical conductivity properties of PEDOT polymers synthesized at $72 \mathrm{kGy}$ in the presence of $\mathrm{HCl}$. Few drops of PEDOT suspension obtained after irradiation were deposited by spin coating onto a glass substrate at a speed of $1000 \mathrm{rpm}$ for $60 \mathrm{~s}$. The spin-coated film was doped with an acetonitrile solution containing $10 \mathrm{mM}$ in $\mathrm{NOBF}_{4}$. Then, in order to dry the film and to quantitatively evaporate the solvent, the substrate was heated up for $30 \mathrm{~min}$ in a hot plat at $130^{\circ} \mathrm{C}$. The thickness of the dried PEDOT film was measured by using a 3 Veeco Dektak 150 surface profiler, while the resistance of the film was evaluated by the means of a Kelvin four-point probe technique. The conductivity, $\rho\left(\mathrm{S} \mathrm{cm}^{-1}\right)$, was calculated based on the following equation:

$$
\rho=\left(\frac{\pi}{\ln 2} \times \frac{\mathrm{V}}{\mathrm{I}} \times \mathrm{t}\right)^{-1}
$$

where $\mathrm{V}$ is the voltage $(\mathrm{V}), \mathrm{I}$ the applied current $(\mathrm{A})$ and $\mathrm{t}$ the film thickness $(\mathrm{cm})$.

\section{Results and discussion}

\subsection{Mechanistic study of EDOT oxidation in aqueous solution at $\mathbf{p H} \sim 0$}

With the aim to check the influence of the acidity of the medium on the oxidation and polymerization of EDOT, aqueous solutions containing $1 \mathrm{mM}$ in EDOT were prepared in the presence of either $\mathrm{HClO}_{4}$ or $\mathrm{HCl}$ at a concentration of $1 \mathrm{M}$. The $\mathrm{pH}$ values of both solutions were measured with a $\mathrm{pH}$-meter and found close to 0 . Before irradiation, the acidic solutions were both transparent and their spectra are identical and similar to that of neutral aqueous solution containing $1 \mathrm{mM}$ in EDOT (Lattach et al., 2013). As in the case of neutral aqueous medium, EDOT is characterized by two absorption maxima at 235 and $255 \mathrm{~nm}$ which are features of $\pi$ - 
$\pi^{*}$ electronic transitions in the thiophene rings as shown in Figure 1. Also, at these two wavelengths, the molar extinction coefficients have the same values as in neutral medium (Lattach et al., 2013).

Aqueous solutions containing $1 \mathrm{mM}$ in EDOT and $1 \mathrm{M}$ in either $\mathrm{HCl}$ or $\mathrm{HClO}_{4}$ (at $\mathrm{pH} \sim 0$ ) were degassed with $\mathrm{N}_{2} \mathrm{O}$ and irradiated at increasing doses up to $8 \mathrm{kGy}$. Interestingly, the evolution with the dose of the absorption spectra of the two acidic solutions (that with $\mathrm{HCl}$ and that with $\mathrm{HClO}_{4}$ ) is strictly similar. Thus, only one series of spectra, which traduces both evolutions, is displayed on Figure 1. As observed, the intensity of the UV-visible absorption spectrum of EDOT decreases with increasing dose. This indicates the progressive consumption of EDOT monomers upon $\gamma$ irradiation in presence of $\mathrm{HCl}$ or $\mathrm{HClO}_{4}$. This decrease of EDOT absorption at 235 and $255 \mathrm{~nm}$ parallels an increase in the absorbancy at higher wavelengths. Note that an isosbestic point already observed and explained in our previous works (Lattach et al., 2013) is present at around $270 \mathrm{~nm}$. From the values of the extinction coefficients at 235 and $255 \mathrm{~nm}$ (Lattach et al., 2013) and starting from $1 \mathrm{mM}$ in EDOT, one can deduce the variation in EDOT concentration as a function of the dose (Insert of Figure 1). The initial yield of EDOT oxidation at $\mathrm{pH} \sim 0$ in presence of either $\mathrm{HCl}$ or $\mathrm{HClO}_{4}$, $\mathrm{G}_{\mathrm{ox}}$, can then be experimentally estimated since it corresponds to the value of the initial slope of the curve displayed in insert of Fig. 1. In particular, it can be deduced from an exponential fit:

$$
\mathrm{G}_{\mathrm{ox}}=2.5 \pm 0.5 \times 10^{-7} \mathrm{~mol} \mathrm{~J}^{-1}
$$

In the case of $\mathrm{HClO}_{4}$, this yield of EDOT oxidation is close to the value of $\mathrm{G}\left(\mathrm{HO}^{\bullet}\right)$ at $\mathrm{pH} \sim 0\left(2.8 \times 10^{-7} \mathrm{~mol} \mathrm{~J}^{-1}\right.$, equation (9)) and much lower than that of $\mathrm{G}\left(\mathrm{HO}^{*}\right)$ $+\mathrm{G}\left(\mathrm{H}^{*}\right)$ at the same $\mathrm{pH}\left(6.2 \times 10^{-7} \mathrm{~mol} \mathrm{~J}^{-1}\right)$. This result demonstrates that in the case of $\mathrm{HClO}_{4}, \mathrm{HO}^{\bullet}$ radicals quantitatively oxidize EDOT monomers (as already demonstrated in neutral aqueous media), while $\mathrm{H}^{\bullet}$ atoms remain totally unreactive towards EDOT oxidation.

Similarly, in the case of $\mathrm{HCl}$, the oxidation yield, $\mathrm{G}_{\mathrm{ox}}$, is close to the value of $\mathrm{G}\left(\mathrm{Cl}_{2}{ }^{-}\right)$at $\mathrm{pH} \sim 0\left(2.8 \times 10^{-7} \mathrm{~mol} \mathrm{~J}^{-1}\right.$, equation (14)) and remains much lower than that of $\mathrm{G}\left(\mathrm{Cl}_{2}{ }^{\circ}\right)+\mathrm{G}\left(\mathrm{H}^{*}\right)$ at the same $\mathrm{pH}\left(6.2 \times 10^{-7} \mathrm{~mol} \mathrm{~J}^{-1}\right)$. This highlights once again the fact that $\mathrm{H}^{\bullet}$ radicals are unreactive towards EDOT monomers. This proves moreover 
than $\mathrm{Cl}_{2}{ }^{\circ-}$ radicals, such as hydroxyl radicals, quantitatively oxidize EDOT monomers thanks to their high redox potential.

\subsection{Radio-induced synthesis of PEDOT polymers at $\mathrm{pH} \sim 0$}

As demonstrated, under $\mathrm{N}_{2} \mathrm{O}$ at $\mathrm{pH} \sim 0$, in presence of $\mathrm{HClO}_{4}$ or with $\mathrm{HCl}, \mathrm{HO}$ or $\mathrm{Cl}_{2}{ }^{\circ-}$ quantitatively oxidize EDOT. If we assume, in both cases, effective oxidation yields of $2.8 \times 10^{-7} \mathrm{~mol} \mathrm{~J}^{-1}$, the dose needed for quantitative polymerization of $10 \mathrm{mM}$ in EDOT amounts to $72 \mathrm{kGy}$ at $\mathrm{pH} \sim 0$ according to equation (15).

Acidic aqueous solution containing $10 \mathrm{mM}$ in EDOT and $1 \mathrm{M}$ in $\mathrm{HClO}_{4}$ and acidic aqueous solution containing $10 \mathrm{mM}$ in EDOT and $1 \mathrm{M}$ in $\mathrm{HCl}$ were then both irradiated at $72 \mathrm{kGy}$ under $\mathrm{N}_{2} \mathrm{O}$ atmosphere. Also, for comparison purpose a neutral aqueous solution containing $10 \mathrm{mM}$ in EDOT in the absence of acids was irradiated under $\mathrm{N}_{2} \mathrm{O}$ at the same dose. The pictures of the three solutions after irradiation (in insert) as well as their UV-Vis absorption spectra are displayed on Figure 2.

After a $72 \mathrm{kGy}$-irradiation, the solution prepared in neutral medium appears yellow (photography $\mathrm{c}$ in insert of Figure 2) and its absorption spectrum (spectrum c of Figure 2) displays an intense absorption band at around $350 \mathrm{~nm}$ in total agreement with our previous works (Lattach et al., 2013; Cui et al., 2017; Lattach et al., 2014). This band was shown to be characteristic of PEDOT oligomers produced in the neutral medium by water radiolysis. Differently, after irradiation at $72 \mathrm{kGy}$, the solutions prepared at $\mathrm{pH} \sim 0$ in the presence of $\mathrm{HCl}$ (photography a in insert of Figure 2) or in the presence of $\mathrm{HClO}_{4}$ (photography b) both appear as dark blue suspensions, which is the typical color of PEDOT polymers when obtained in their oxidized state (Heuer et al., 2002; Pei et al., 1994). Remarkably, when considering the absorption spectra of the two acidic solutions irradiated at $72 \mathrm{kGy}$ in presence of $\mathrm{HCl}$ (spectrum a of Figure 2) or $\mathrm{HClO}_{4}$ (spectrum b), two shoulders are observed in both cases at 350 and $450 \mathrm{~nm}$, which can be attributed to the presence, in very acidic medium, of PEDOT polymers prepared upon irradiation. As a matter of fact, PEDOT polymers are known to usually display, in solution, characteristic peaks in this wavelength region which are assigned to $\pi-\pi^{*}$ transitions in the polymer backbones.

In addition to these shoulders, a large absorption band was observed in both cases at around $700 \mathrm{~nm}$ in the case of $\mathrm{HCl}$ (spectrum a) and in the case of $\mathrm{HClO}_{4}$ 
(spectrum b). This large band can be considered as polaron or bipolaron bands, which are both characteristic of PEDOT polymers when obtained in their oxidized state (p-type doping) (Rumbau et al., 2007; Kudrjasova et al., 2014). This will be further demonstrated in the paper. This interesting result, which is in total agreement with the colors of the irradiated solutions, demonstrates that contrarily to PEDOT oligomers produced in neutral medium, polymers synthesized under the same atmosphere $\left(\mathrm{N}_{2} \mathrm{O}\right)$ at $\mathrm{pH} \sim 0$ are found doped. The doping of radiosynthesized PEDOT polymers should result from the presence in the medium of considerable amounts (1 M) of hydrochloric acid or perchloric acid. PEDOT polymers produced in presence of either $\mathrm{HCl}$ or $\mathrm{HClO}_{4}$ seem to be in the same oxidized state since the doping bands are located at approximatively the same wavelength.

\subsection{Chemical and structural characterizations of PEDOT polymers synthesized in presence of $\mathrm{HCl}$ at $\mathrm{pH} \sim 0$}

Since the results obtained in very acidic aqueous medium are quite similar (after a 72 kGy-irradiation) whatever the nature of the acid, we can conclude that the reactivity of $\mathrm{Cl}_{2}{ }^{--}$onto EDOT monomers is comparable to that of $\mathrm{HO}^{*}$, leading to PEDOT polymers with similar absorption properties. Since we already studied, in previous works, the reactivity of hydroxyl radicals onto EDOT monomers in neutral medium and characterized the polymers produced in these experimental conditions, we decided to focus our work on the reactivity of an alternative oxidizing species, namely $\mathrm{Cl}_{2}{ }^{\circ}$, but this time in very acidic medium, and chose to characterize in more detail PEDOT polymers produced by radiolysis at $72 \mathrm{kGy}$ in the presence of $\mathrm{HCl}$.

Attenuated total reflectance Fourier transform infrared spectroscopy (ATRFTIR) was used to confirm the successful radiation induced synthesis of PEDOT polymers under $\mathrm{N}_{2} \mathrm{O}$ after a $72 \mathrm{kGy}$-irradiation of a very acidic aqueous solution containing $10 \mathrm{mM}$ in EDOT in the presence of $1 \mathrm{M}$ in $\mathrm{HCl}$. After irradiation, in order to remove water and EDOT monomer residues, irradiated solution was washed and dried. The dried dark blue powder was then characterized by ATR-FTIR spectroscopy and its spectrum was compared with the spectrum of pure EDOT monomers within wavenumber region from 4000 to $600 \mathrm{~cm}^{-1}$ (Figure 3). It is quite important to note that the difference between the intensity and the resolution of PEDOT polymers 
spectrum and those of EDOT monomers spectrum originates from the way of deposition on the ATR-FTIR crystal: liquid phase deposition in case of EDOT against solid phase deposition in case of PEDOT.

As observed on Figure 3, ATR-FTIR spectra of pure EDOT and of radiosynthesized PEDOT are in good agreement with literature. All the characteristic bands of PEDOT polymers can be identified without any ambiguity, which confirms the effective polymerization of EDOT monomers. The vibration modes of the $\mathrm{C}-\mathrm{S}$ bond can be located at 835, 902 and $981 \mathrm{~cm}^{-1}$ (Kvarnström et al., 1999; Ghosh et al., 2014). The vibration bands at 1054 and $1182 \mathrm{~cm}^{-1}$ are attributed to stretching of the $\mathrm{C}$ O-C bond in the ethylenedioxy group (Kvarnström et al., 1999; Dams et al., 2006). The stretching vibrations of $\mathrm{C}=\mathrm{C}$ in thiophene ring are observed at 1390 and $1471 \mathrm{~cm}^{-}$ , while the bands at 1226 and $1349 \mathrm{~cm}^{-1}$ originate from C-C bonds (Lattach et al., 2014; Kvarnström et al., 1999; Ghosh et al., 2014). Remarkably, the ATR-FTIR spectrum of EDOT displays typical bands at $755 \mathrm{~cm}^{-1}$, attributed to the $=\mathrm{C}-\mathrm{H}$ in-plane and out-of-plane deformation vibrations, which are not detected in the infrared spectrum of PEDOT (Hagiwara et al., 1989). The disappearance of these bands upon irradiation highlights the involvement of $\alpha, \alpha^{\prime}$-coupling reactions during PEDOT growth (Lattach et al., 2013; Lattach et al., 2014; Akimoto et al., 1986) (see Scheme 1), confirming that the dose of $72 \mathrm{kGy}$ used during irradiation leads, as expected, to quantitative polymerization of EDOT.

The ATR-FTIR spectrum recorded after a $72 \mathrm{kGy}$-irradiation displays the typical bands of PEDOT polymers. However, at close up view of PEDOT spectrum, it is possible to detect at $1640 \mathrm{~cm}^{-1}$ the presence of an additional less common band, which nevertheless has already been notified in literature specifically in the case of PEDOT polymers doped with chloride ions (Bahry et al., 2018). It is worth noting that this peak which results from polymers doping has never been observed in our previous works concerning radiation induced synthesis of PEDOT in neutral aqueous media. The presence of this band in acidic medium at $\mathrm{pH} \sim 0$ demonstrates the doping of PEDOT by chloride anions in full agreement with the results obtained by UV-vis absorption spectroscopy, since a large absorption band at $700 \mathrm{~nm}$ was observed (Figure 2). Note that chloride ions should come from the quantitative dissociation in aqueous solution of hydrochloric acid (a strong acid) which is present at very high concentration. These chloride anions are thus found to remain in PEDOT powder even after washing procedure. It is worth noting that PEDOT polymers which were 
prepared in the presence of $\mathrm{HClO}_{4}$ instead of $\mathrm{HCl}$, should be doped by perchlorate ions $\left(\mathrm{ClO}_{4}^{-}\right.$coming from perchloric acid dissociation) instead of chloride ions, which explains the doping band also observed in this case at around $700 \mathrm{~nm}$ (Figure 2).

Size exclusion chromatography (SEC) was used to estimate the number average molecular weight $\left(\mathrm{M}_{\mathrm{n}}\right)$, the weight average molecular weight $\left(\mathrm{M}_{\mathrm{w}}\right)$ and the peak molecular weight $\left(\mathrm{M}_{\mathrm{p}}\right.$, at the maximum of the highest peak of the chromatogram) of PEDOT polymers radiosynthesized, in the presence of $1 \mathrm{M}$ in hydrochloric acid, at an absorbed dose of $72 \mathrm{kGy}$ (Figure 4). We chose to use and to measure the molar masses, $\mathrm{M}_{\mathrm{p}}$, at the maxima of the peaks since the calculation of the average molecular weight, $\mathrm{M}_{\mathrm{n}}$, can be skewed by the overlapping of the peaks of the chromatogram. The more intense peak observed on Figure 4, peak (a), corresponds to the molar mass $\left(\mathrm{M}_{\mathrm{p}}\right)$ of $1128 \mathrm{~g} \mathrm{~mol}^{-1}$ (obtained with a polystyrene calibration). This indicates the presence of approximatively 8 EDOT units per PEDOT chain. This is consistent with our recent results concerning PEDOT polymers prepared by radiolysis in dichloromethane solvent (Bahry et al., 2018). Note that PEDOT polymers with higher molecular weights $\left(M_{w}>3000\right)$ were also detected indicating that longer polymer chains were formed (up to 20 EDOT units). Interestingly, SEC experiments highlighted the low polydispersity of radiosynthesized PEDOT polymers since the polydispersity index, $\mathrm{M}_{\mathrm{w}} / \mathrm{M}_{\mathrm{n}}$, was found equal to 1.27 , which is consistent with a relatively well controlled step-by-step polymerization reaction (Aldabbagh et al., 2008; Kwak and Matyjaszewski, 2010).

\subsection{Morphological characterization of PEDOT polymers synthesized in presence of $\mathrm{HCl}$ at $\mathrm{pH} \sim 0$}

The study by UV-Vis absorption spectrophotometry and by ATR-FTIR spectroscopy demonstrates the successful preparation by the way of radiation chemistry of PEDOT polymers in very acidic aqueous solution under $\mathrm{N}_{2} \mathrm{O}$ atmosphere. Also, the polymers were found doped with chloride anions which come from $\mathrm{HCl}$ acid used to adjust the $\mathrm{pH}$ of the medium.

In order to check the morphology of PEDOT polymers obtained by $\gamma$-radiolysis in very acidic aqueous medium, SEM microscopy was used. We considered in particular PEDOT powders obtained after the $72 \mathrm{kGy}$-irradiation of an acidic aqueous 
solution containing EDOT monomers $(10 \mathrm{mM}$ in EDOT and $1 \mathrm{M}$ in $\mathrm{HCl})$ and after water evaporation. A typical SEM image, recorded after deposition of the dried dark blue PEDOT polymers powder and after its coating with gold, is displayed on Figure 5. In the absence of gold coating, in situ Energy-Dispersive X-ray spectroscopy (EDX) highlighted the presence in the whole sample of sulfur, carbon and oxygen elements (results not shown) underlining the presence of PEDOT in the materials observed in Figure 5. Besides, EDX enabled the detection of an additional chemical element, namely chlorine atom, not present in the organic monomers but found homogeneously dispersed in the deposited solid sample. This finding, in good agreement with our UV-vis and ATR-FTIR spectroscopies results, definitely proves the doping by chloride ions of PEDOT polymers radiosynthesized in acidic medium.

Figure 5 highlights the presence in the deposit of compact spheroidal particles. As explained in our previous works, these globular structures result from the selfassembly of interdigitated PEDOT polymer chains which are neither branched nor networked but nevertheless in weak interactions. These aggregated PEDOT spheroidal particles appear heterogeneous in size with diameters comprised between 200 and $500 \mathrm{~nm}$.

With the aim to definitely demonstrate that the particles observed by SEM are made of PEDOT polymers, AFM microscopy coupled with IR nanospectroscopy was used. Few drops of the dark blue suspension obtained after irradiation (at $72 \mathrm{kGy}$ ) of EDOT acidic aqueous solution (presence of $\mathrm{HCl}$ ) were deposited onto the $\mathrm{ZnSe}$ prism of AFM-IR apparatus leading, after drying, to a thin film which was scanned and imaged by AFM-IR as shown in Figure 6. The topography of the deposited materials as obtained by AFM in contact mode is displayed in Figure 6a. The brighter areas observed in this image correspond to the thicker regions made up of aggregated spheroidal particles with diameters of about few hundreds $\mathrm{nm}$, in agreement with reported results (Wang et al., 2016; Poverenov et al., 2010). Interestingly, these particles have the same size and shape as those previously observed by SEM.

AFM-IR experiments were extended by recording the local infrared absorption spectra of the particles observed in Figure $6 \mathrm{a}$ in the range of 1020-1600 $\mathrm{cm}^{-1}$ (Figure $6 b)$. It is worth noting that all the probed particles were found characterized by the same infrared spectrum, highlighting their single chemical structure. This infrared spectrum fits well with the ATR-FTIR spectrum of PEDOT displayed in Figure 3. 
This demonstrates that the particles observed at present by AFM and earlier by SEM contain without any ambiguity PEDOT polymers.

In order to record the chemical map of the film and in order to check its absorption at a given wavenumber, we scanned its surface by AFM-IR. In particular, in the spectrum of Figure $6 \mathrm{~b}$, we considered the peak at $1478 \mathrm{~cm}^{-1}$ which corresponds to $\mathrm{C}=\mathrm{C}$ stretching band in PEDOT polymers (Kvarnström et al., 1999; Jang et al., 2005). Besides, this band is also observed at $1471 \mathrm{~cm}^{-1}$ in the ATR-FTIR spectrum of PEDOT (Figure 3). We selected the corresponding wavenumber $\left(1478 \mathrm{~cm}^{-1}\right)$ to map the sample and recorded the absorption strength as a function of the tip position onto the surface (Figure 6c). In this figure, the red areas indicate a stronger absorption at the chosen wavenumber which should correspond to a thicker layer of PEDOT deposited onto the prism. When comparing the AFM topographic image (Figure 6a) and the AFM-IR chemical mapping (Figure 6c), one can note that the stronger absorbing areas of Figure $6 \mathrm{c}$ and the thicker regions of Figure 6a are perfectly stackable. This definitely proves that the observed spheroidal particles are mainly composed by PEDOT polymers as expected.

SEM and AFM observations together with EDX spectroscopy and AFM-IR nanospectroscopy characterizations enable us to conclude with certainty that radiolysis under $\mathrm{N}_{2} \mathrm{O}$ of very acidic aqueous solutions (containing EDOT monomers in presence of $1 \mathrm{M}$ in $\mathrm{HCl}$ ) leads to the oxidation of monomers and to the synthesis of PEDOT polymers. The latter are doped with chloride ions and self-assemble into polydisperse globular nanoparticles, the diameters of which remain comprised between 200 and $500 \mathrm{~nm}$ as observed by SEM and AFM.

\subsection{Electrical and electrochemical properties of PEDOT polymers synthesized in presence of $\mathrm{HCl}$ at $\mathrm{pH} \sim 0$}

The morphology of PEDOT polymers radiosynthesized in acidic aqueous solution through EDOT oxidation by $\mathrm{Cl}_{2}{ }^{--}$radicals appears similar to that of PEDOT polymers reported in literature (Wang et al., 2016; Patterson et al., 2017; Kim et al., 2014; Zhou et al., 2015; Mumtaz et al., 2008; Van de Ruit et al., 2013; Louet et al., 2015) and to that of PEDOT polymers we already synthesized by radiolysis either in dichloromethane solvent (Bahry et al., 2018) or in neutral aqueous medium through EDOT oxidation by $\mathrm{HO}^{\bullet}$ radicals (Lattach et al., 2014; Cui et al., 2016). We can then 
conclude that neither the acidity of the medium nor the reactivity of $\mathrm{Cl}_{2}{ }^{\circ-}$ radicals influence the final morphology of PEDOT polymers. Nevertheless, as previously mentioned, the presence of $\mathrm{HCl}$ during the growth process leads to the presence of $\mathrm{Cl}^{-}$ anions into the polymer matrices which induces the doping of PEDOT polymers (Jang et al., 2005) when synthesized in very acidic medium.

In order to investigate electrochemical and electronic properties of PEDOT polymers synthesized by water radiolysis in the presence of $\mathrm{HCl}$ at $\mathrm{pH} \sim 0$ and in order to check whether in situ doping of the polymers (by $\mathrm{Cl}^{-}$anions) affects their band gap, cyclic voltammetry (CV) experiments were undertaken. The purpose was to determine first the oxidation and reduction potentials of radiosynthesized PEDOT polymers, then the energy levels of both their highest occupied molecular orbital (HOMO, from the ionization potential) and their lowest unoccupied molecular orbital (LUMO, from the electronic affinity) and finally their characteristic electronic band gap.

Cyclic voltammetry (CV) was used to check the electrochemical behavior of PEDOT polymers synthesized by radiolysis at $72 \mathrm{kGy}$ in an aqueous solution containing $10 \mathrm{mM}$ in EDOT and $1 \mathrm{M}$ in $\mathrm{HCl}$ under $\mathrm{N}_{2} \mathrm{O}$ atmosphere. In this context, PEDOT powder obtained after irradiation and water evaporation was dissolved in acetonitrile solution containing tetrabutylammonium hexafluorophosphate $\left(\mathrm{TBAPF}_{6}\right.$, used as electrolyte) and then electrochemically studied. The resulting cyclic voltammogram is displayed in Figure 7 together with the characteristic oxidation and reduction peaks of PEDOT polymers.

As observed in cyclic voltammogram of Figure 7, PEDOT oxidation (p-doping process) starts at onset potential, $\mathrm{E}_{\mathrm{ox}}{ }^{\text {onset }}$, of $+1.01 \mathrm{~V}$, whereas PEDOT reduction (ndoping process) occurs at onset potential, $\mathrm{E}_{\text {red }}{ }^{\text {onset }}$, of $-0.03 \mathrm{~V}$. Starting from these two onset potential values, one can calculate, from the equations given in legend of Figure 7, the HOMO and LUMO energy levels of PEDOT radiosynthesized in very acidic medium: $\mathrm{E}_{\mathrm{HOMO}}=-5.44 \mathrm{eV}$ and $\mathrm{E}_{\mathrm{LUMO}}=-4.40 \mathrm{eV}$. Consequently, the corresponding electrochemical band gap, $\mathrm{E}_{\mathrm{g}}{ }^{\mathrm{el}}$, amounts to $1.04 \mathrm{eV}$. This band gap value is found smaller than those (around $1.60 \mathrm{eV}$ ) already reported in literature for PEDOT polymers (Groenendaal et al., 2000; Bahry et al., 2018; Sotzing and Reynolds, 1991). The narrow bandgap found in the present case indicates that polymers radiosynthesized in very acidic medium may possess good electrical conductivity. 
Four-point probe technique was then used to evaluate the electrical conductivity of PEDOT polymers synthesized by radiolysis at $72 \mathrm{kGy}$ in presence of $10 \mathrm{mM}$ in EDOT and $1 \mathrm{M}$ in $\mathrm{HCl}$ under $\mathrm{N}_{2} \mathrm{O}$ atmosphere. PEDOT dark blue suspension obtained after irradiation was deposited by spin coating onto a glass substrate and then doped with $\mathrm{NOBF}_{4}$. The thickness of the film was then measured by a surface profiler and the conductivity was finally determined by four-point probe technique. The conductivity of PEDOT polymers synthesized in this work in very acidic aqueous medium was found to be $3.3 \times 10^{-3} \mathrm{~S} \mathrm{~cm}^{-1}$, which is of the same order of magnitude as the conductivities of PEDOT we already synthesized by radiolysis in neutral aqueous solutions or in organic solvents and remains close to the conductivities reported in literature for PEDOT polymers produced by conventional methods (Rumbau et al., 2007; Cui et al., 2016; Bahry et al., 2018; Van de Ruit et al., 2013).

Cyclic voltammetry characterizations together with four-point probe experiments allow us to deduce and to note down the interesting electronic properties (band gap and conductivity) of PEDOT polymers synthesized in this work in very acidic aqueous medium by the way of our alternative radiolytic method. It is worth noting that the $\pi$-conjugated systems present all along the polymer chains and the oxidized states induced by polymers doping should both contribute to the good electrical conductivity of organic conducting materials (Jang et al., 2005; Stöcker et al., 2012). Nevertheless, it seems that in situ doping of PEDOT polymers by $\mathrm{Cl}^{-}$ anions (when prepared by radiolysis in very acidic medium in the presence of $\mathrm{HCl}$ ) does not drastically enhance their conductivity. Although the relatively good electrical conductivity of PEDOT polymers synthesized, at $\mathrm{pH} \sim 0$, in presence of $\mathrm{HCl}$ is in good agreement with the small band gap deduced from $\mathrm{CV}$ experiments, its value still needs to be enhanced for instance by increasing the conjugation length into the polymers and also by controlling the stacking and the organization of the polymer chains into the sample (Saunders, 1978; Hawkins and Ratcliffe, 2000).

\section{Conclusion}

In the present paper, we undertook the use of $\gamma$-irradiation in order to radiolytically prepare, for the first time, conducting polymers in very acidic aqueous media and then to study their morphological, optical and electrical properties. We 
extended our strategy based on radiation chemistry to the oxidation and then polymerization, under $\mathrm{N}_{2} \mathrm{O}$ and at $\mathrm{pH} \sim 0$, of EDOT monomers, in presence of either $\mathrm{HClO}_{4}$ or $\mathrm{HCl}$ as strong inorganic acids, by exploiting the strong oxidizing power of $\mathrm{HO} \cdot$ (in case of $\mathrm{HClO}_{4}$ ) or $\mathrm{Cl}_{2}{ }^{-}$(in case of $\mathrm{HCl}$ ) radicals produced by $\gamma$-radiolysis. We demonstrated that both $\mathrm{HO} \cdot$ and $\mathrm{Cl}_{2}{ }^{*-}$ radicals quantitatively oxidize EDOT monomers, while $\mathrm{H}^{*}$ atoms remain totally unreactive towards EDOT oxidation. The determination of the yield of EDOT oxidation by $\mathrm{HO} \cdot$ and $\mathrm{Cl}_{2}{ }^{-}$enabled us to evaluate the dose needed for quantitative polymerization of EDOT polymers at $\mathrm{pH} \sim$ 0 , in the presence of either $\mathrm{HClO}_{4}$ or $\mathrm{HCl}$. Evidently, we also highlighted the PEDOT nature of the products by the use of complementary characterization techniques.

The as-prepared PEDOT polymers, which form dark blue suspensions just after irradiation, are characterized, in the presence of $\mathrm{HClO}_{4}$ or $\mathrm{HCl}$, by a large absorption band at around $700 \mathrm{~nm}$. As highlighted by ATR-FTIR spectroscopy and EnergyDispersive X-ray (EDX) analysis, this band results from the in situ doping of PEDOT polymers radiosynthesized in very acidic aqueous solutions. Besides, SEC chromatography highlighted the low polydispersity of PEDOT polymers synthesized at $\mathrm{pH} \sim 0$ and demonstrated that their polymer chains contain up to 20 EDOT units. It is worth noting that, differently, in neutral aqueous solution, radiation induced EDOT oxidation leads to a yellow suspension which contains, instead of doped polymers, PEDOT oligomers (with shorter chain lengths) in the neutral state (not doped).

After deposition from the aqueous phase, the observations and characterizations made by SEM and AFM microscopies, EDX spectroscopy and AFM-IR nanospectroscopy showed that water radiolysis in the presence of $\mathrm{HCl}$ leads to the production of PEDOT polymers (doped with $\mathrm{Cl}^{-}$anions) which self-assemble into polydisperse globular particles (size comprised between 200 and $500 \mathrm{~nm}$ ). Since PEDOT morphology in very acidic medium is comparable to that of PEDOT polymers obtained in neutral aqueous medium, one can conclude that neither the acidity of the medium (presence of $\mathrm{HCl}$ at $1 \mathrm{M}$ ) nor the reactivity of $\mathrm{Cl}_{2}{ }^{*-}$ radicals affect the final morphology of PEDOT polymers.

Electronic properties of PEDOT polymers synthesized in very acidic medium, in the presence of $\mathrm{HCl}$, were finally evaluated thanks to $\mathrm{CV}$ experiments and fourpoint probe measurements. The conductivity of the polymers synthesized in this work, in very acidic aqueous medium, was found relatively high, but remains of the same 
order of magnitude as the conductivities of PEDOT polymers we previously synthesized by radiolysis in neutral aqueous media. Interestingly, the band gap value corresponding to the polymers prepared by radiolysis at $\mathrm{pH} \sim 0$ was found smaller than those already reported in literature for PEDOT. Although the relatively good electrical conductivity of PEDOT polymers synthesized at $\mathrm{pH} \sim 0$ is in good agreement with the small bandgap, its value needs to be enhanced by increasing the conjugation length into the polymer chains and by controlling their nanostructuration.

From now on, our radiolytic methodology fully appears as a promising alternative method for the preparation, not only in neutral solutions but also in acidic aqueous media, of conducting polymers with enhanced properties. The considerable electrical conductivity of the polymers radiosynthesized in very acidic aqueous solutions and, above all, their in situ doping and their low band gap foreshadow further advances in the field of conducting polymers synthesis and applications.

\section{Acknowledgements}

We acknowledge the financial support from the China Scholarship Council (CSC). We thank Matthieu Gervais and Cyrille Sollogoub (PIMM, ENSAM and CNAM) for SEC experiments and SEM observations. 


\section{References}

Li, C., Bai, H., Shi, G., 2009. Conducting polymer nanomaterials: electrosynthesis and applications. Chem. Soc. Rev. 38, 2397-409.

Shirakawa, H., 2001. The discovery of polyacetylene film: the dawning of an era of conducting polymers (Nobel Lecture). Angew. Chem. Int. Ed. 40, 2574-2580.

Heeger, A. J., 2001a. Semiconducting and metallic polymers: the fourth generation of polymeric materials. J. Phys. Chem. B 105, 8475-8491.

Heeger, A. J., 2001b. Semiconducting and metallic polymers: The fouth gerernation of polymeric materials (Nobel Lecture). Angew. Chem. Int. Ed. 40, 2591-2611.

MacDiarmid, A. G., 2001. "Synthetic metals": a novel role for organic polymers (Nobel Lecture). Angew. Chem. Int. Ed. 40, 2581-2590.

Cho, B., Park, K. S., Baek, J., Oh, H. S., Koo Lee, Y.-E., Sung, M. M., 2014. Singlecrystal poly(3,4-ethylenedioxythiophene) nanowires with ultrahigh conductivity. Nano Lett. 14, 3321-3327.

Balint, R., Cassidy, N. J., Cartmell, S. H., 2014. Conductive polymers: towards a smart biomaterial for tissue engineering. Acta Biomater. 10, 2341-2353.

Heuer, H. W., Wehrmann, R., Kirchmeyer, S., 2002. Electrochromic window based on conducting poly(3,4-ethylenedioxythiophene)-poly(styrene sulfonate). Adv. Funct. Mater. 12, 89-94.

Na, S.-I., Kim, S.-S., Jo, J., Kim, D.-Y., 2008. Efficient and flexible ITO-free organic solar cells using highly conductive polymer anodes. Adv. Mater. 20, 4061-4067.

Roncali, J., Blanchard, P., Frère, P., 2005. 3,4-Ethylenedioxythiophene (EDOT) as a versatile building block for advanced functional $\pi$-conjugated systems. J. Mater. Chem. 15, 1589-1610.

Groenendaal, L., Jonas, F., Freitag, D., Pielartzik, H., Reynolds, J. R., 2000. Poly(3,4ethylenedioxythiophene) and its derivatives: past, present, and future. Adv. Mater. 12, 481-494.

Zhang, X., MacDiarmid, A. G., Manohar, S. K., 2005. Chemical synthesis of PEDOT nanofibers. Chem. Commun. 5328-5330.

Bashir, T., Naeem, J., Skrifvars, M., Persson, N. K., 2014. Synthesis of electro-active membranes by chemical vapor deposition (CVD) process. Polym. Adv. Technol. $25,1501-1508$.

Xiao, R., Cho, S., Liu, R., Lee, S. B., 2007. Controlled electrochemical synthesis of conductive polymer nanotube structures. J. Am. Chem. Soc 129, 4483-4489. 
Akoudad, S., Roncali, J., 1998. Electrochemical synthesis of poly(3,4ethylenedioxythiophene) from a dimer precursor. Synth. Met. 93, 111-114.

Dong, S., Li, J., Yun, C., Jian-Rong, Z., Jun-Jie, Z., 2013. Microwave-assisted in situ synthesis of graphene/PEDOT hybrid and its application in supercapacitors. ChemPlusChem 78, 227-234.

Rumbau, V., Pomposo, J. A., Eleta, A., Rodriguez, J., Grande, H., Mecerreyes, D., Ochoteco, E., 2007. First enzymatic synthesis of water-soluble conducting poly(3,4-ethylenedioxythiophene). Biomacromolecules 8, 315-317.

Lattach, Y., Deniset-Besseau, A., Guigner, J. M., Remita, S., 2013. Radiation chemistry as an alternative way for the synthesis of PEDOT conducting Polymers under "soft" conditions. Radiat. Phys. Chem. 82, 44-53.

Cui, Z., Coletta, C., Bahry, T., Marignier, J.-L., Guigner, J.-M., Gervais, M., Baiz, S., Goubard, F., Remita, S., 2017. A novel radiation chemistry-based methodology for the synthesis of PEDOT/Ag nanocomposites. Mater. Chem. Front. 1, 879-892.

Lattach, Y., Coletta, C., Ghosh, S., Remita, S., 2014. Radiation-induced synthesis of nanostructured conjugated polymers in aqueous solution: fundamental effect of oxidizing species. Chemphyschem 15, 208-218.

Cui, Z., Coletta, C., Rebois, R., Baiz, S., Gervais, M., Goubard, F., Aubert, P. H., Dazzi, A., Remita, S., 2016. Radiation-induced reduction-polymerization route for the Synthesis of PEDOT conducting polymers. Radiat. Phys. Chem. 119, 157-166.

Tehrani, P., Kanciurzewska, A., Crispin, X., Robinson, N., Fahlman, M., Berggren, M., 2007. The effect of $\mathrm{pH}$ on the electrochemical over-oxidation in PEDOT:PSS films. Solid State Ion. 177, 3521-3527.

Ouyang, J., 2013. Solution-processed PEDOT:PSS films with conductivities as indium tin oxide through a treatment with mild and weak organic acids. ACS Appl. Mater. Interfaces 5, 13082-13088.

Yun, D.-J., Jeong, Y. J., Ra, H., Kim, J.-M., Park, J. H., Park, S., An, T. K., Seol, M., Park, C. E., Jang, J., Chung, D. S., 2016. Effective way to enhance the electrode performance of multiwall carbon nanotube and poly(3,4ethylenedioxythiophene):poly(styrene sulfonate) composite using $\mathrm{HCl}$-methanol treatment. J. Phys. Chem. C 120, 10919-10926.

Spinks, J. W. T., Woods, R. J., 1990. An introduction to radiation chemistry. John Wiley \& Sons, Inc. 3, 273.

Ferradini, C., Jay-Gerin, J.-P., 1999. La radiolyse de l'eau et des solutions aqueuses: historique et actualité. Can. J. Chem. 77, 1542-1575.

Ferradini, C., Jay-Gerin, J. P., 2000. The effect of pH on water radiolysis: a still open question - a minireview. Res. Chem. Intermed. 26, 549-565. 
Schwarz, H. A., 1981. Free radicals generated by radiolysis of aqueous solutions. J. Chem. Educ. 58, 101.

Buxton, G. V., Greenstock, C. L., Helman, W. P., Ross, A. B., 1988. Critical review of rate constants for reactions of hydrated electrons, hydrogen atoms and hydroxyl radicals (.OH/·O-) in aqueous solution. J. Phys. Chem. Ref. Data 17, 513-886.

Hart, E. J., 1969. Research potentials of the hydrated electron. Acc. Chem. Res. 2, 161-167.

Coletta, C., Cui, Z., Archirel, P., Pernot, P., Marignier, J.-L., Remita, S., 2015. Electron-induced growth mechanism of conducting polymers: a coupled experimental and computational investigation. J. Phys. Chem. B 119, 5282-5298.

Saunders, B. B., 1978. Reactions of thiophene with radiolytically produced radicals. 2. The solvated electron and the hydrogen atom. J. Phys. Chem. 82, 151-154.

Jayson, G. G., Parsons, B. J., Swallow, A. J., 1973. Some simple, highly reactive, inorganic chlorine derivatives in aqueous solution. Their formation using pulses of radiation and their role in the mechanism of the Fricke dosimeter. J. Chem. Soc., Faraday Trans. 1 69, 1597-1607.

Elliot, A. J., Geertsen, S., Buxton, G. V., 1988. Oxidation of thiocyanate and iodide ions by hydrogen atoms in acid solutions. J. Chern. Soc., Faraday Trans. I 84, 1101-1112.

Schwarz, H. A., Dodson, R. W., 1984. Equilibrium between hydroxyl radicals and thallium(II) and the oxidation potential of $\mathrm{OH}$ (aq). J. Phys. Chem. 88, 36433647.

Mlekodaj, R. L., 1995. Basic units and concepts in radiation exposures. American Chemical Society, Washington, D.C. , 243, pp 23-37.

Pei, Q. B., Zuccarello, G., Ahlskogt, M., Ingan, O., 1994. Electrochromic and highly stable poly(3,4-ethylenedioxythiophene) switches between opaque blue-black and transparent sky blue. Polymer 35, 1347-1351.

Kudrjasova, J., Herckens, R., Penxten, H., Adriaensens, P., Lutsen, L., Vanderzande, D., Maes, W., 2014. Direct arylation as a versatile tool towards thiazolo[5,4d] thiazole-based semiconducting materials. Org. Biomol. Chem. 12, 4663-4672.

Kvarnström, C., Neugebauer, H., Blomquist, S., H.J. Ahonenc, J. Kankarec, Ivaska, A., 1999. In situ spectroelectrochemical characterization of poly(3,4ethylenedioxythiophene). Electrochim. Acta 44, 2739-2750.

Ghosh, S., Remita, H., Ramos, L., Dazzi, A., Deniset-Besseau, A., Beaunier, P., Goubard, F., Aubert, P. H., Brisset, F., Remita, S., 2014. PEDOT nanostructures synthesized in hexagonal mesophases. New J. Chem. 38, 1106-1115.

Dams, R., Vangeneugden, D., Vanderzande, D., 2006. Plasma deposition of thiophene derivatives under atmospheric pressure. Chem. Vap. Deposition 12, 719-727. 
Hagiwara, T., Yamaura, M., Sato, K., Hirasaka, M., Iwata, K., 1989. Synthesis and properties of poly(3,4-dimethoxythiophene). Synth. Met. 32, 367-369.

Akimoto, M., Furukawa, Y., Takeuchi, H., Harada, I., 1986. Correlation between vibrational spectra and electrical conductivity of polythiophene. Synth. Met. 15, 353-360.

Bahry, T., Cui, Z., Deniset-Besseau, A., Gervais, M., Sollogoub, C., Bui, T.-T., Remita, S., 2018. An alternative radiolytic route for synthesizing conducting polymers in an organic solvent. New J. Chem. 42, 8704-8716.

Aldabbagh, F., Zetterlund, P. B., Okubo, M., 2008. Improved control in nitroxidemediated radical polymerization using supercritical carbon dioxide. Macromolecules 41, 2732-2734.

Kwak, Y., Matyjaszewski, K., 2010. Photoirradiated atom transfer radical polymerization with an alkyl dithiocarbamate at ambient temperature. Macromolecules 43, 5180-5183.

Wang, Q., Chueh, C. C., Eslamian, M., Jen, A. K. Y., 2016. Modulation of PEDOT:PSS $\mathrm{pH}$ for efficient inverted perovskite solar cells with reduced potential loss and enhanced stability. ACS Appl. Mater. Interfaces 8, 3206832076.

Poverenov, E., Li, M., Bitler, A., Bendikov, M., 2010. Major effect of electropolymerization solvent on morphology and electrochromic properties of PEDOT films. Chem. Mater. 22, 4019-4025.

Jang, J., Chang, M., Yoon, H., 2005. Chemical sensors based on highly conductive poly(3,4-ethylenedioxythiophene) nanorods. Adv. Mater. 17, 1616-1620.

Patterson, J. P., Xu, Y., Moradi, M.-A., Sommerdijk, N. A. J. M., Friedrich, H., 2017. CryoTEM as an advanced analytical tool for materials chemists. Acc. Chem. Res. 50, 1495-1501.

Kim, N., Kee, S., Lee, S. H., Lee, B. H., Kahng, Y. H., Jo, Y. R., Kim, B. J., Lee, K., 2014. Highly conductive PEDOT:PSS nanofibrils induced by solution-processed crystallization. Adv. Mater. 26, 2268-2272.

Zhou, J., Anjum, D. H., Lubineau, G., Li, E. Q., Thoroddsen, S. T., 2015. Unraveling the order and disorder in poly(3,4ethylenedioxythiophene)/poly(styrenesulfonate) nanofilms. Macromolecules 48, 5688-5696.

Mumtaz, M., Lecommandoux, S., Cloutet, E., Cramail, H., 2008. Synthesis of calibrated poly(3,4-ethylenedioxythiophene) latexes in aqueous dispersant media. Langmuir 24, 11911-11920.

Van de Ruit, K., Cohen, R. I., Bollen, D., Van Mol, T., Yerushalmi-Rozen, R., Janssen, R. A. J., Kemerink, M., 2013. Quasi-one dimensional in-plane conductivity in filamentary films of PEDOT:PSS. Adv. Funct. Mater. 23, 57785786. 
Louet, C., Cantin, S., Dudon, J.-P., Aubert, P.-H., Vidal, F., Chevrot, C., 2015. A comprehensive study of infrared reflectivity of poly(3,4-ethylenedioxythiophene) model layers with different morphologies and conductivities. Sol. Energy Mater. Sol. Cells 143, 141-151.

Sotzing, G. A., Reynolds, J. R., 1991. Poly(3,4-ethylenedioxythiophene) (PEDOT) prepared via electrochemical polymerization of EDOT, 2,2'-bis(3,4ethylenedioxythiophene) (BiEDOT), and their TMS derivatives. Adv. Mater. 9, 795-798.

Stöcker, T., Köhler, A., Moos, R., 2012. Why does the electrical conductivity in PEDOT:PSS decrease with PSS content? A study combining thermoelectric measurements with impedance spectroscopy. J. Polym. Sci., Part B: Polym. Phys. 50, 976-983.

Hawkins, S. J., Ratcliffe, N. M., 2000. A study of the effects of acid on the polymerisation of pyrrole, on the oxidative polymerisation of pyrrole and on polypyrrole. J. Mater. Chem. 10, 2057-2062. 


\section{Scheme 1}

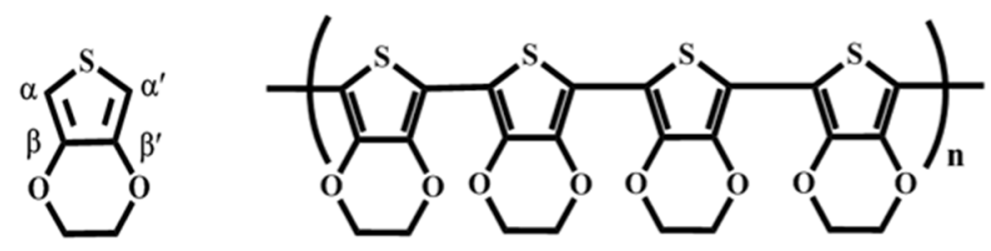

\section{3,4-ethylenedioxythiophene} (EDOT)
Poly(3,4-ethylenedioxythiophene) (PEDOT)

Scheme 1. Chemical structures of 3,4-ethylenedioxythiophene (EDOT) monomer and poly(3,4-ethylenedioxythiophene) (PEDOT) polymer. EDOT structure shows free $\alpha, \alpha^{\prime}$ positions where coupling reactions occur. 


\section{Figure 1}

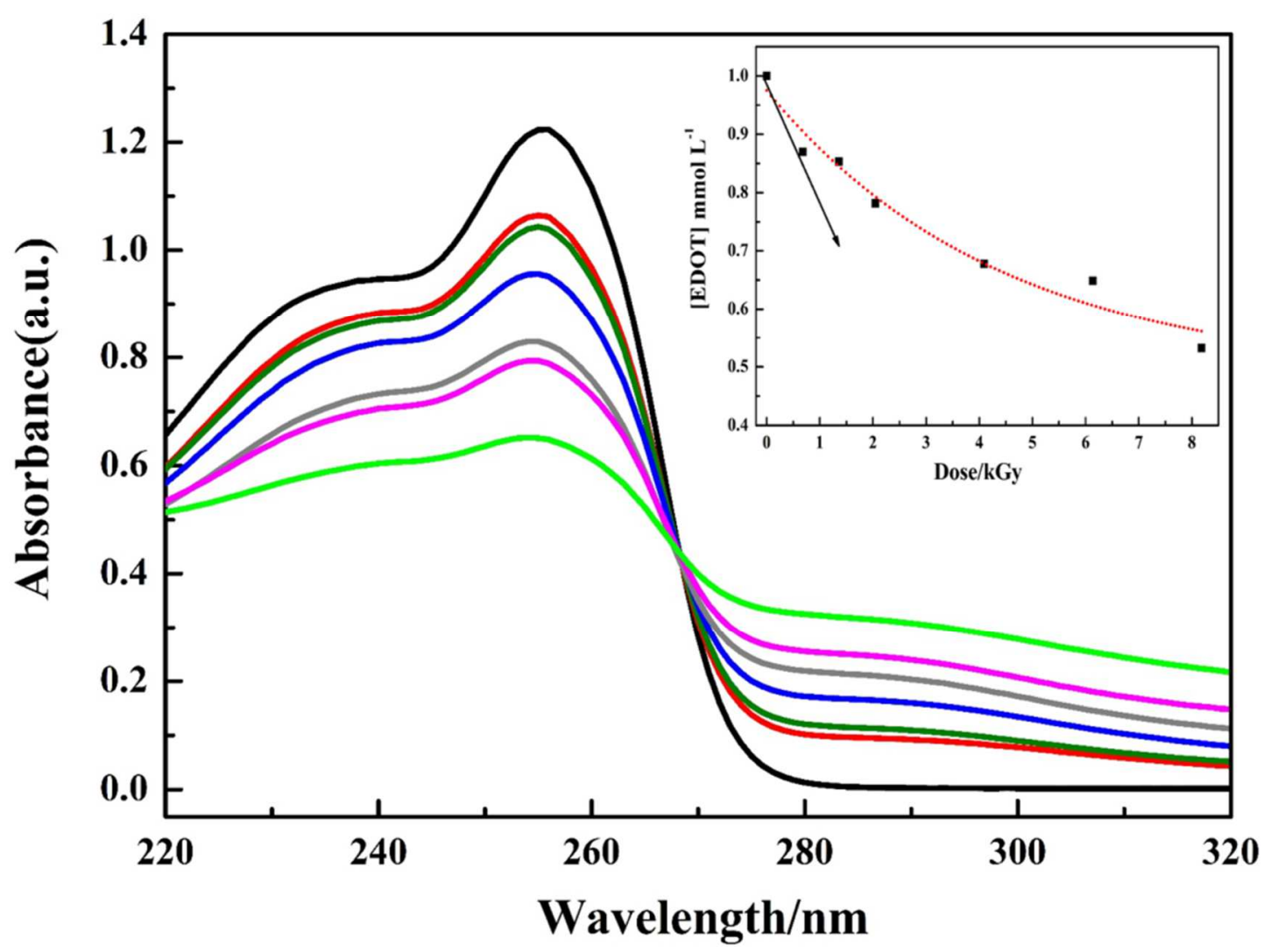

Figure 1- Evolution of UV-vis absorption spectrum of EDOT aqueous solutions (1 $\mathrm{mM})$ added with $\mathrm{HCl}$ or $\mathrm{HClO}_{4}(1 \mathrm{M}, \mathrm{pH}=0)$ under $\mathrm{N}_{2} \mathrm{O}$ atmosphere as a function of the dose (from 0 to $8 \mathrm{kGy}$ ). The optical path length was $0.2 \mathrm{~cm}$. The reference was water. Insert: variation of EDOT concentration as a function of the dose. The radiolytic yield of EDOT oxidation corresponds to the initial slope of the curve. 


\section{Figure 2}

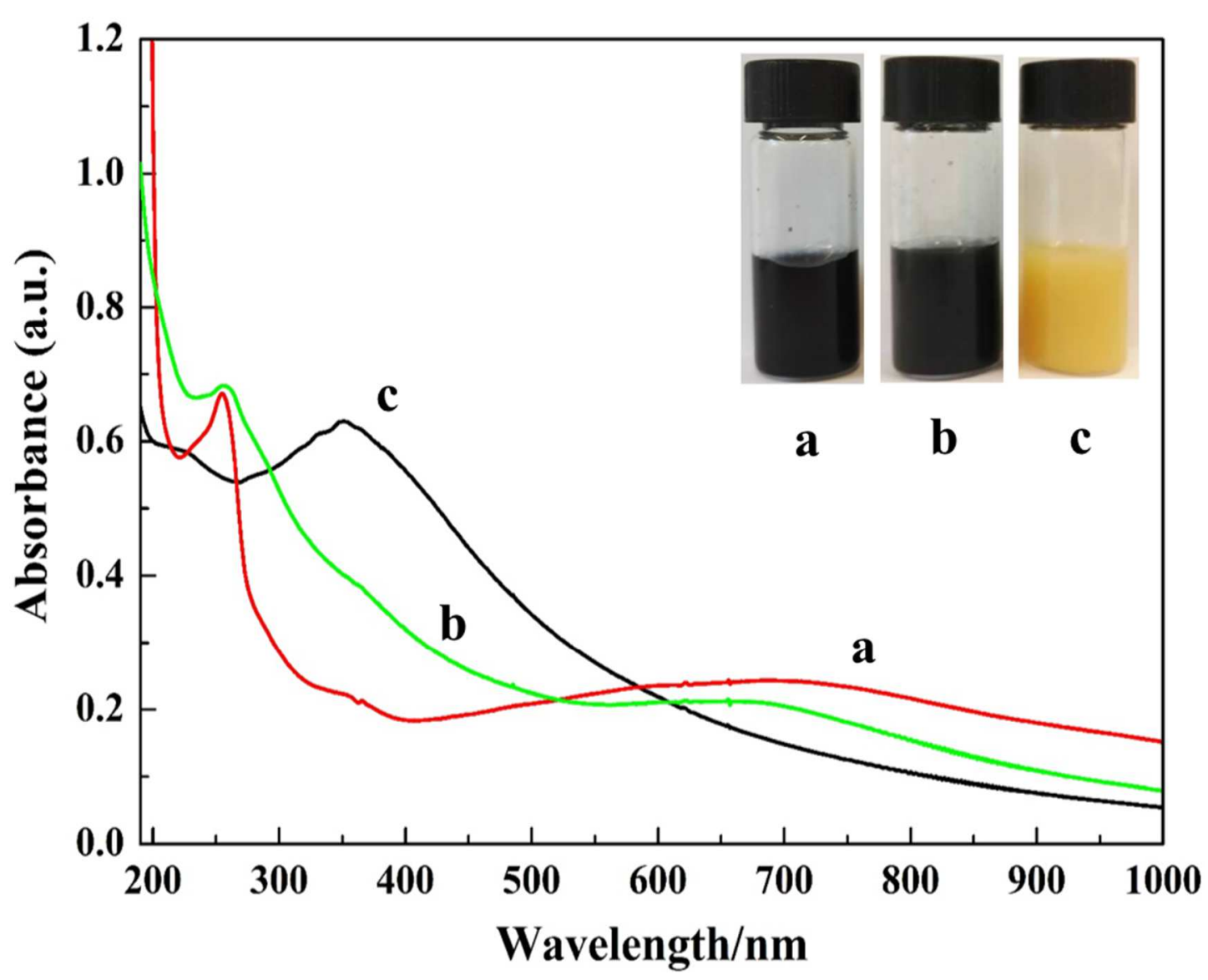

Figure 2- UV-Vis absorption spectra of PEDOT polymers synthesized after $72 \mathrm{kGy}-$ irradiation of aqueous solutions containing $10 \mathrm{mM}$ in EDOT under $\mathrm{N}_{2} \mathrm{O}$ atmosphere (a) in presence of $\mathrm{HCl}(1 \mathrm{M})$ at $\mathrm{pH}=0$, (b) in presence of $\mathrm{HClO}_{4}(1 \mathrm{M})$ at $\mathrm{pH}=0$ and (c) in the absence of acids at neutral $\mathrm{pH}$. All the spectra were recorded after 10 times dilution. The optical path length was $0.2 \mathrm{~cm}$. The reference was water. Insert: photographies of the corresponding aqueous solutions. 


\section{Figure 3}

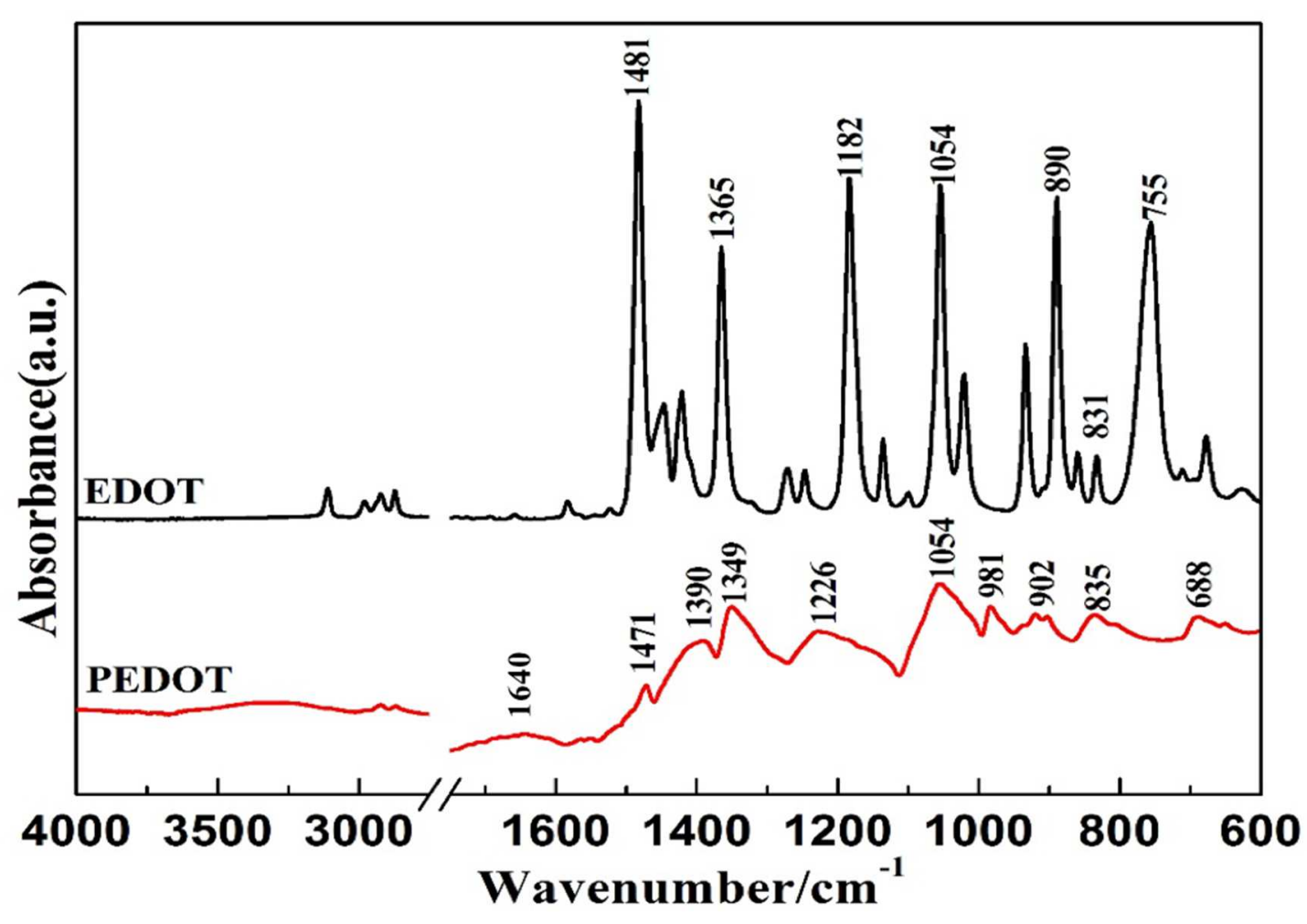

Figure 3- ATR-FTIR spectra of pure EDOT monomers and of PEDOT polymers radiosynthesized through a $72 \mathrm{kGy}$-irradiation of an aqueous solution containing 10 $\mathrm{mM}$ in EDOT under $\mathrm{N}_{2} \mathrm{O}$ atmosphere in presence of $\mathrm{HCl}(1 \mathrm{M})$ at $\mathrm{pH} 0$. 


\section{Figure 4}

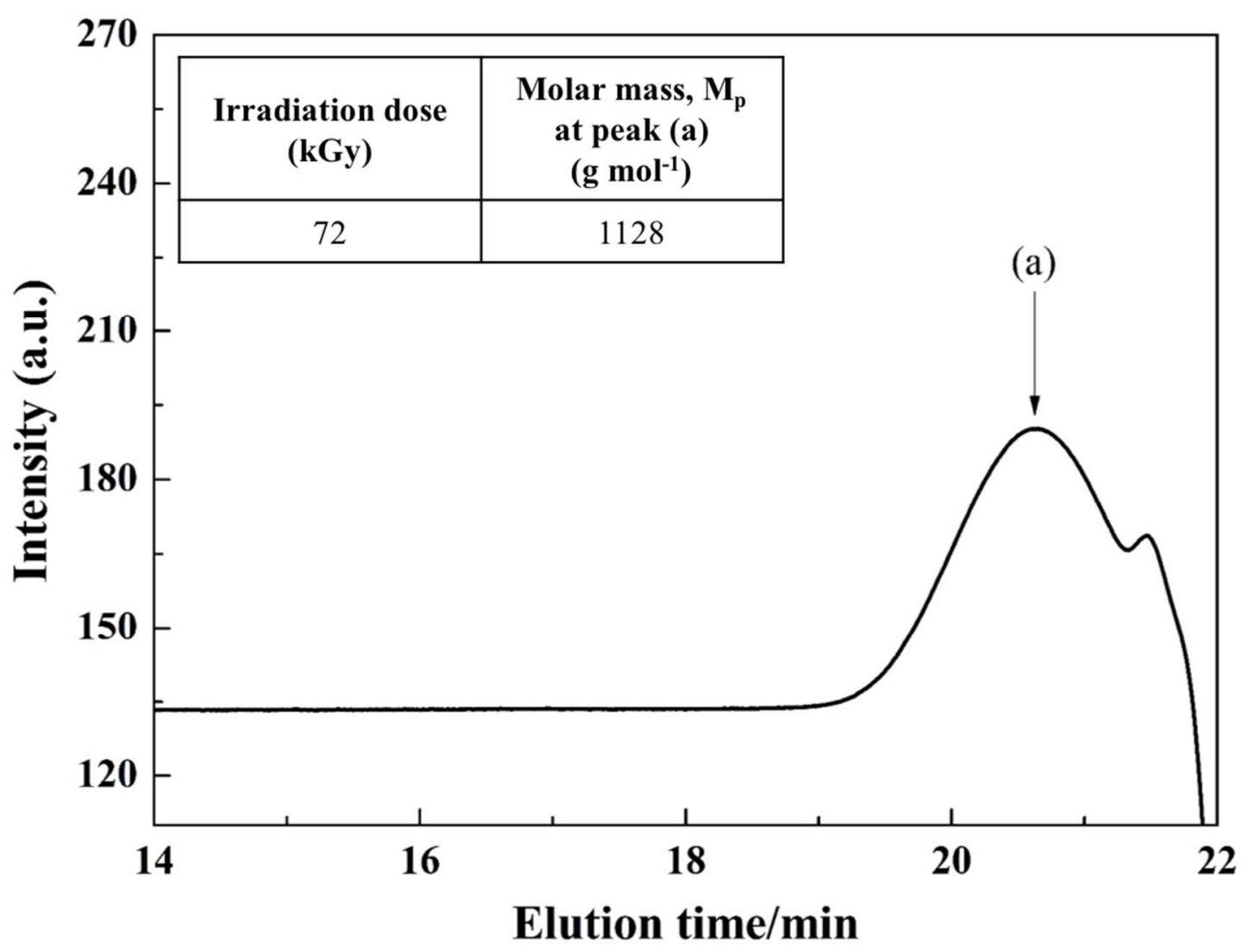

Figure 4- SEC chromatogram of PEDOT polymers radiosynthesized through a 72 kGy-irradiation of an aqueous solution containing $10 \mathrm{mM}$ in EDOT and $1 \mathrm{M}$ in $\mathrm{HCl}$ ( $\mathrm{pH}=0)$ under $\mathrm{N}_{2} \mathrm{O}$ atmosphere. 


\section{Figure 5}

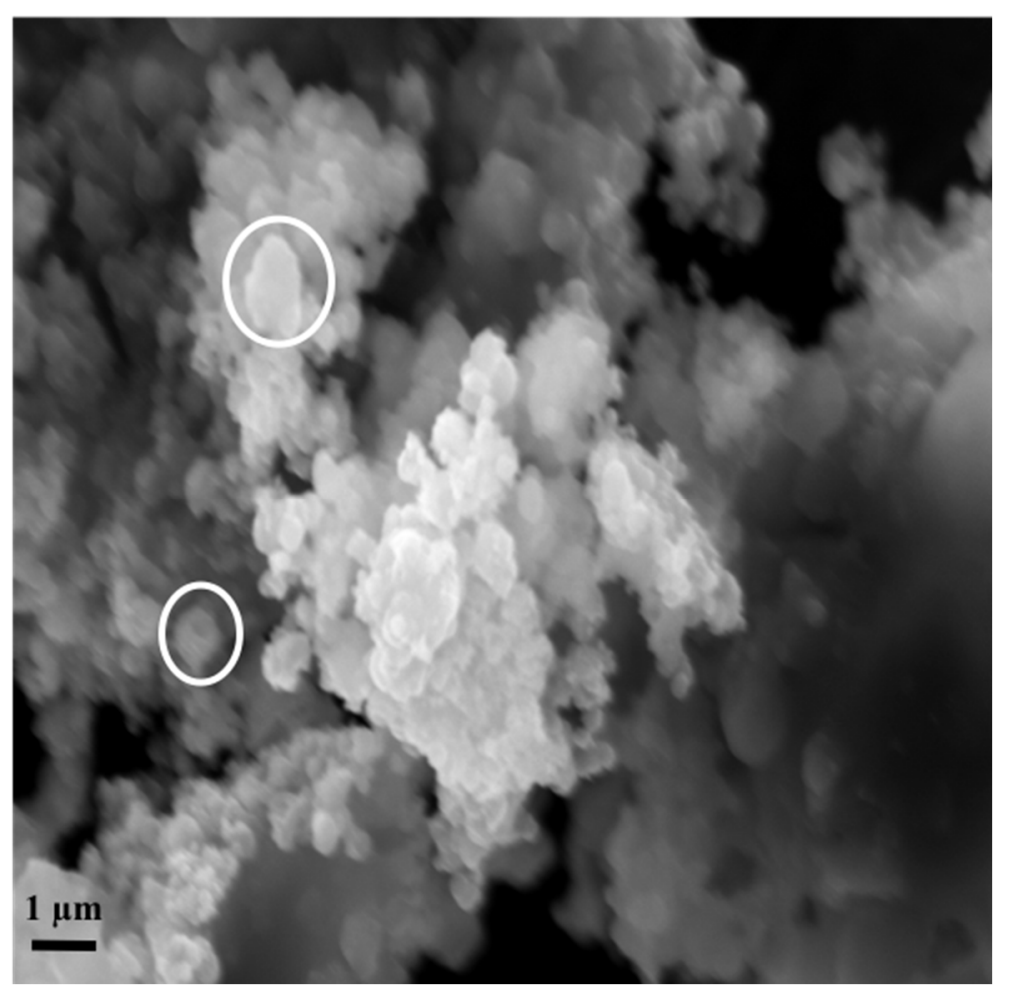

Figure 5- SEM image of dried PEDOT polymers powder. The powder was obtained after solvent evaporation. PEDOT polymers were synthesized by gamma-radiolysis at $72 \mathrm{kGy}$ of an aqueous solution containing $10 \mathrm{mM}$ in EDOT and $1 \mathrm{M}$ in $\mathrm{HCl}(\mathrm{pH}=0)$ under $\mathrm{N}_{2} \mathrm{O}$ atmosphere. 


\section{Figure 6}
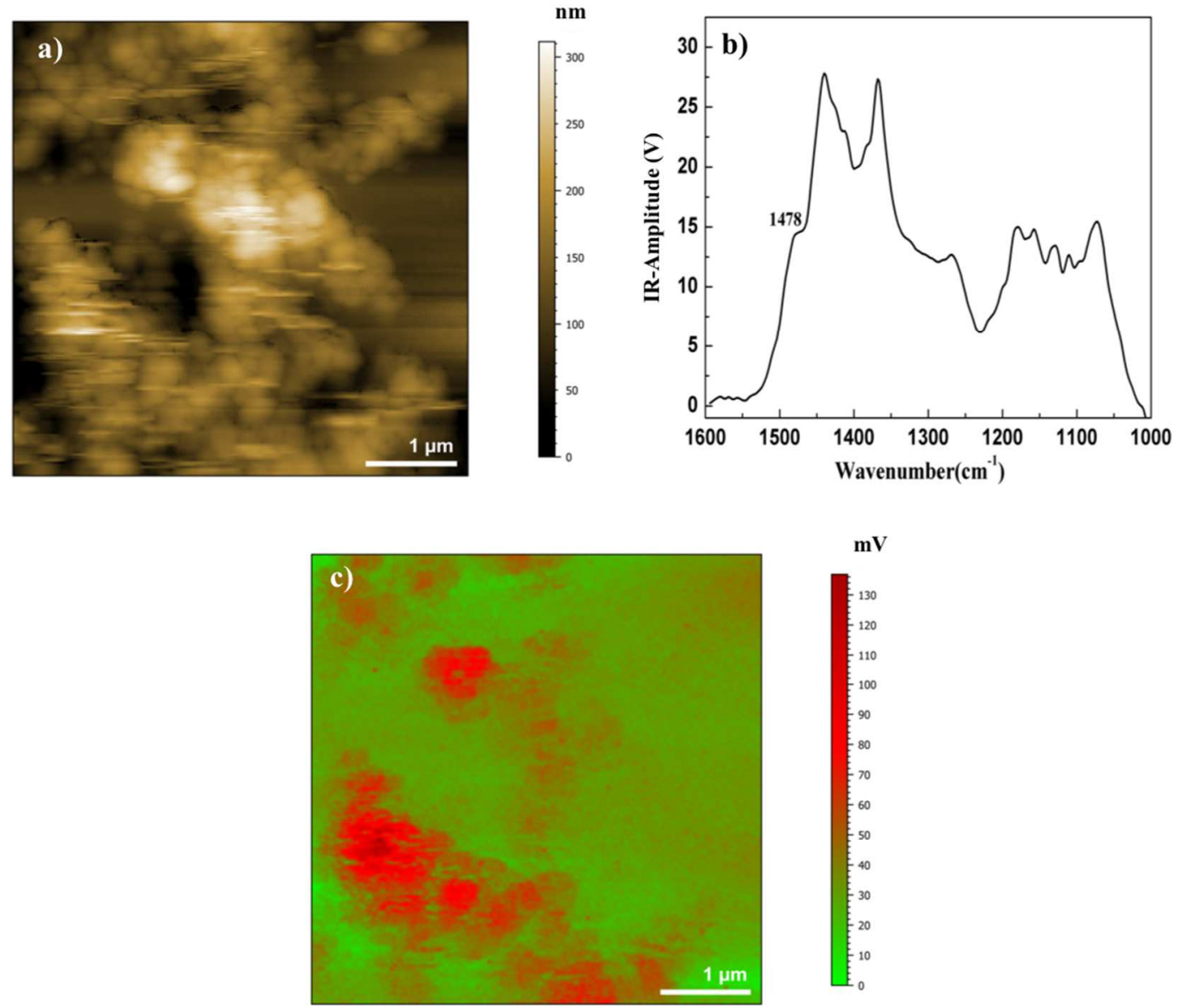

Figure 6- AFM-IR images of PEDOT polymers after deposition onto the upper surface of ZnSe prism. PEDOT polymers were synthesized by gamma-radiolysis at 72 $\mathrm{kGy}$ of an aqueous solution containing $10 \mathrm{mM}$ in EDOT and $1 \mathrm{M}$ in $\mathrm{HCl}(\mathrm{pH}=0)$ under $\mathrm{N}_{2} \mathrm{O}$ atmosphere. (a) AFM topographic image of PEDOT polymers in contact mode. (b) AFM-IR spectrum of PEDOT. (c) AFM-IR chemical mapping of PEDOT with the IR source tuned to the $\mathrm{C}-\mathrm{C}$ band at $1478 \mathrm{~cm}^{-1}$. 


\section{Figure 7}

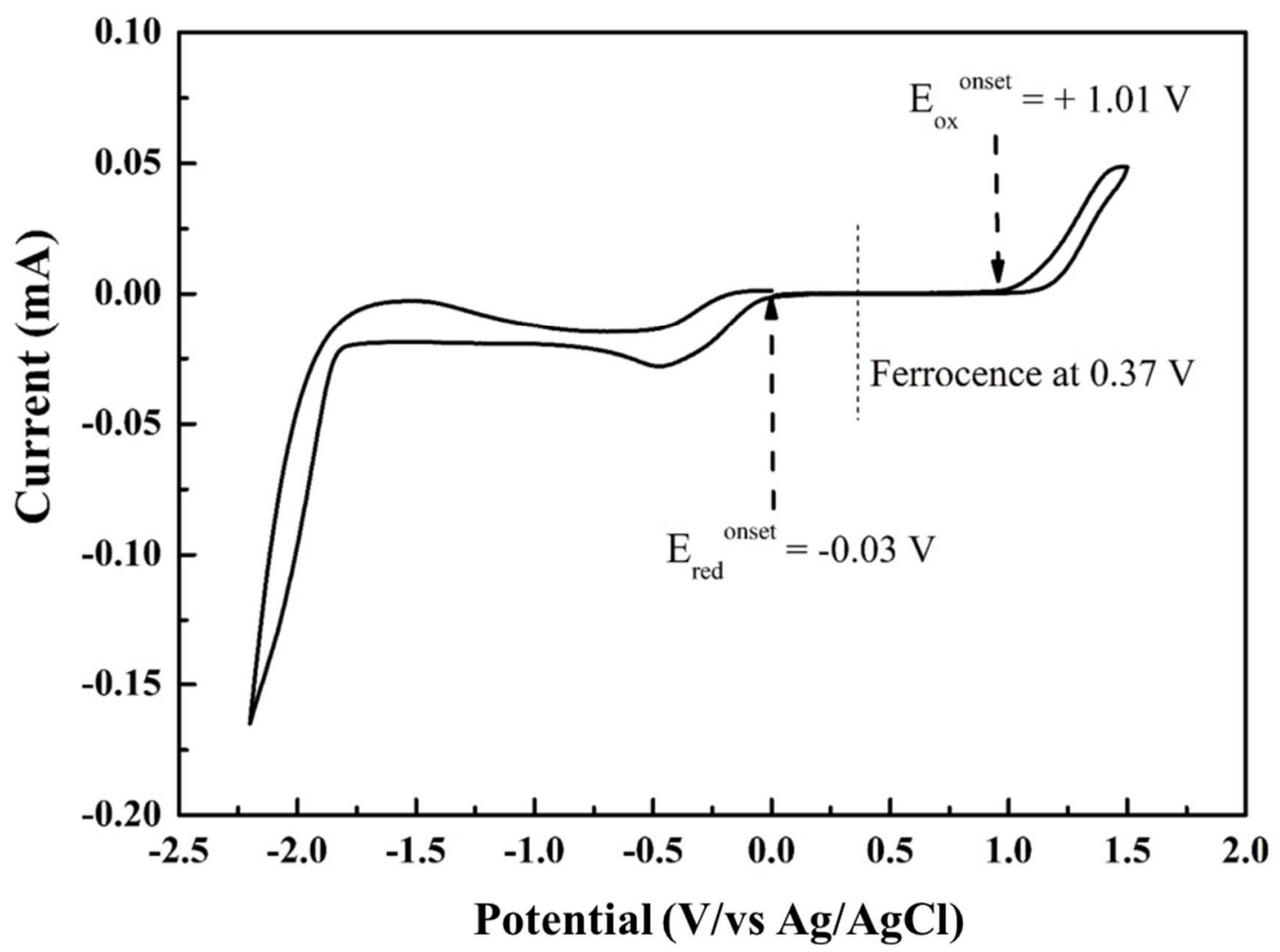

Figure 7- Cyclic voltammogram of PEDOT polymers recorded in acetonitrile containing $0.1 \mathrm{M}$ of $\mathrm{TBAPF}_{6}$ at a scan rate of $20 \mathrm{mV} \mathrm{s}^{-1}$. PEDOT polymers were synthesized by gamma-radiolysis at $72 \mathrm{kGy}$ of an aqueous solution containing $10 \mathrm{mM}$ in EDOT and $1 \mathrm{M}$ in $\mathrm{HCl}(\mathrm{pH}=0)$ under $\mathrm{N}_{2} \mathrm{O}$ atmosphere. Redox potential of ferrocenium/ferrocene $(\mathrm{Fc}+\mathrm{Fc})$ was measured to calibrate the pseudo reference electrode ( $0.37 \mathrm{~V}$ vs. $\mathrm{Ag} / \mathrm{AgCl}$ in the present study). The HOMO/LUMO energetic levels of PEDOT are determined as follows: $\mathrm{E}_{\mathrm{HOMO}}(\mathrm{eV})$ from ionization potential = $4.8-\mathrm{e}\left(\mathrm{E}_{\mathrm{ox}}{ }^{\text {onset }}-0.37\right)$ and $\mathrm{E}_{\mathrm{LUMO}}(\mathrm{eV})$ from electronic affinity $=-4.8-\mathrm{e}\left(\mathrm{E}_{\mathrm{red}}{ }^{\text {onset }}-\right.$ 0.37) where e is the elementary charge. The electrochemical band gap can then be deduced: $\mathrm{E}_{\mathrm{g}}{ }^{\mathrm{el}}=\mathrm{E}_{\mathrm{LUMO}}-\mathrm{E}_{\mathrm{HOMO}}(\mathrm{eV})$. 


\section{Table of Content Graphic}

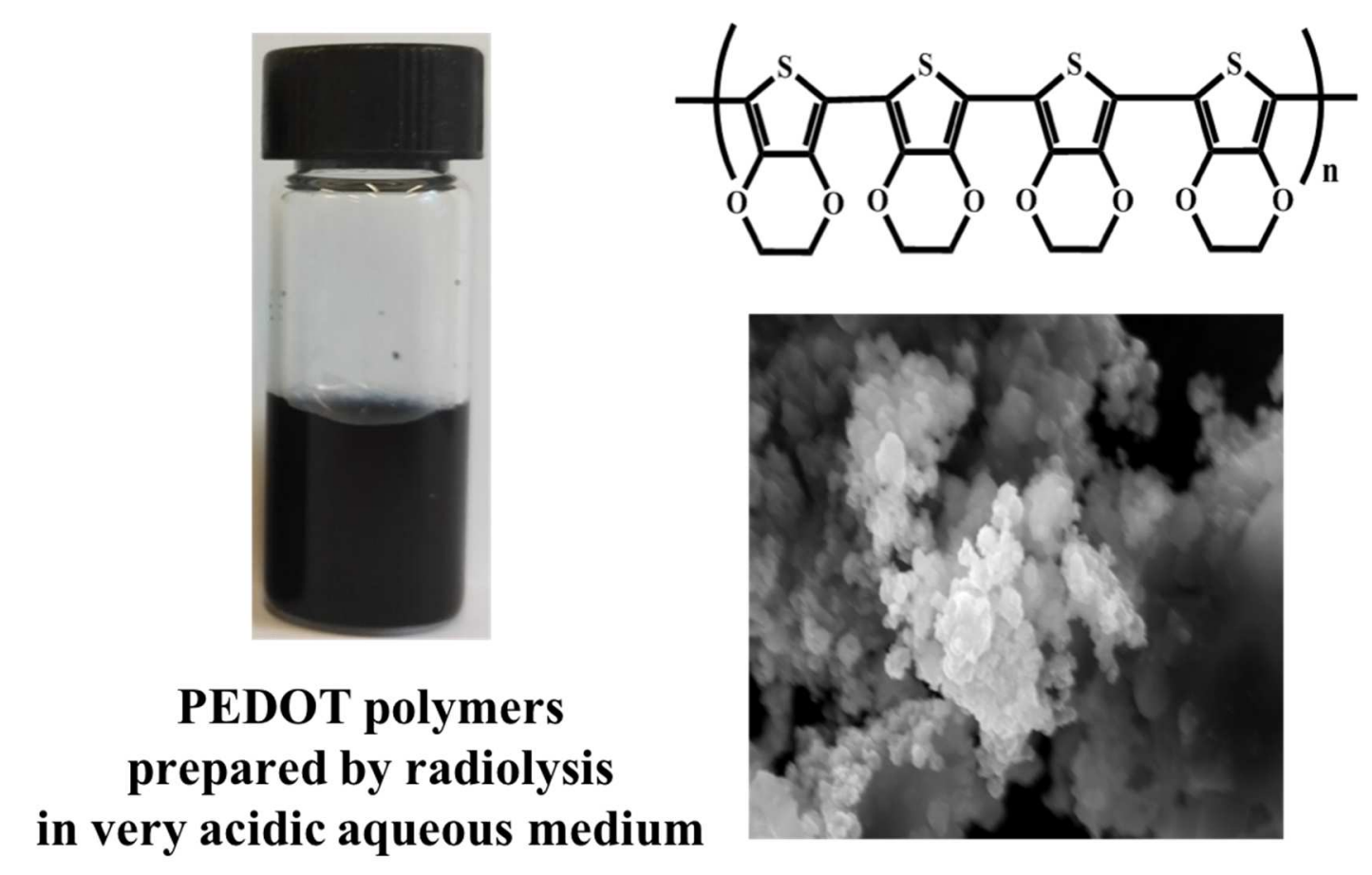

